\title{
A review and critique of assessment instruments for patients with persistent pain
}

\author{
Karen Grimmer-Somers' \\ Nic Vipond ${ }^{2}$ \\ Saravana Kumar' \\ Gillian Hall ${ }^{2}$ \\ 'Centre for Allied Health Evidence, \\ University of South Australia, \\ Australia; ${ }^{2}$ Accident Compensation \\ Corporation, Wellington, New Zealand
}

Correspondence: Karen Grimmer-Somers Director, Centre for Allied Health Evidence, University of South Australia, City East Campus, North Tce,Adelaide 5000 , Australia

Tel +6I 883022769

Fax $+6 \mid 883022766$

Email karen.grimmer-somers@unisa. edu.au

\begin{abstract}
Background: Early identification of individuals at risk of developing persistent pain is important to decrease unnecessary treatment costs and disability. However there is scant comprehensive information readily available to assist clinicians to choose appropriate assessment instruments with sound psychometric and clinical properties.
\end{abstract}

Objective: A national insurer commissioned the development of a compendium of assessment instruments to identify adults with, or at-risk of developing, persistent pain. This paper reports on the instrument identification and review process.

Methods: A comprehensive systematic literature review was undertaken of assessment instruments for persistent pain of noncancer origin, and their developmental literature. Only assessment instruments which were developed for patients with pain, or tested on them, were included. A purpose-built 'Ready Reckoner' scored psychometric properties and clinical utility.

Results: One hundred sixteen potentially useful instruments were identified, measuring severity, psychological, functional and/or quality of life constructs of persistent pain. Forty-five instruments were short-listed, with convincing psychometric properties and clinical utility. There were no standard tests for psychometric properties, and considerable overlap of instrument purpose, item construct, wording, and scoring.

Conclusion: No one assessment instrument captured all the constructs of persistent pain. While the compendium focuses clinicians' choices, multiple instruments are required for comprehensive assessment of adults with persistent pain.

Keywords: persistent pain, assessment, psychometric properties, evidence-base, clinical utility

\section{Background}

An evidence-based practitioner integrates the best available research evidence with clinical judgment and patient preferences, when assessing and treating. ${ }^{1}$ Standardized assessment instruments are available for many health conditions. These initially served as checklists for health practitioners to consider essential elements in history taking. ${ }^{2}$ Nowadays, they are used to predict disability, assess risk, and identify appropriate treatment strategies. ${ }^{2-4}$ A comprehensive health assessment should incorporate information from relevant standardized instruments with a sound history, clinical tests and clinical judgment. ${ }^{1-4}$

This paper deals with assessment instruments for 'persistent', or 'chronic pain'. Different health care providers use different philosophies and techniques when assessing patients with extended pain histories. ${ }^{2-4}$ Siddall and Cousins ${ }^{5}$ defined 'persistent (or extended) pain' as "pain that exists beyond three months" (p. 511), a definition recently reiterated by Cousins. ${ }^{6}$ However Blyth, Cousins, and colleagues applied a similar definition to 'chronic pain' ${ }^{7-10}$ For this paper, we use the term 'persistent pain' to identify "pain that persisted beyond expected healing times."

Inappropriate treatment for patients with persistent pain results in higher costs. $^{9-11}$ There is convincing evidence that early identification of patients at-risk of 
developing persistent pain reduces disability and increases return-to-work rates. ${ }^{9-14}$ This paper reports on a systematic literature review that identified and critically appraised assessment instruments for persistent pain. The review was commissioned by the New Zealand Accident Compensation Corporation, New Zealand's sole, 24-hour, no fault injury insurer and rehabilitation purchaser. This organization is committed to providing health care providers with evidence-based resources. The outcome of this review was a compendium of high quality assessment instruments to assist health practitioners to identify patients with, or at risk of, persistent pain.

\section{Methods}

\section{Project purpose}

The systematic literature review identified psychometrically sound, clinically-useful assessment instruments for persistent pain, for use by multidisciplinary health care teams, or individual practitioners, in face-to-face or telephone situations, and in different locations (large hospitals, rural practices, primary and secondary health care environments).

\section{Reference group}

An expert multidisciplinary reference group assisted the literature review team.

\section{Search strategy}

A comprehensive approach was taken to identify persistent pain assessment instruments (Appendix 1). The search identified 1) any published questionnaire, survey, instrument or rating scale developed primarily to assess persistent (noncancer) pain in adults, as well as instruments which had been developed for other purposes, and subsequently tested on this patient group and 2) relevant peer-reviewed published background literature for each identified instrument.

\section{Background literature}

Developmental literature reported the instrument's psychometric properties. This usually reflected results of psychometric testing, the instrument's performance with different patient groups, and/or validation of instrument translation in other languages. Epidemiological literature reported threshold/cut points or population norms from population-application of the instrument.

\section{Exclusion criteria}

Instruments were excluded if they dealt with specific health conditions or body areas, were unavailable in English, were not fully described for clinical application, did not specifically assess noncancer persistent pain, and/or had no background literature.

\section{Critical appraisal}

Psychometric properties are reported and interpreted differently. ${ }^{2-4}$ Terminology differs depending on health discipline, philosophy of pain mechanisms, the research paradigm used, the purpose of testing, and common usage. This review applied a published classification of psychometric tests for consistency of interpretation. ${ }^{4}$

\section{Project-specific scoring system}

The lack of any published scoring system to rate the quality of assessment instruments for psychometric properties and clinical utility prompted the development of a purpose-built scoring system for this review (Ready Reckoner). This system gave equal weighting to 19 elements of psychometric properties and clinical utility (total score 19) (Figure 1), comprising:

- Evidence of validity testing (face, content and construct validity, sensitivity, factor analysis)

- Evidence of reliability testing (inter-tester, intra-tester, test-retest, internal consistency)

- Availability of instructions for administration, and ease of literacy

- Efficiency of administration using limited number of items

- Capacity of manual score

- Efficient (short) instrument administration time

- Published thresholds/cut points, and/or normative values, specific (or able to be extrapolated) to New Zealand (NZ) persistent pain patients

- Relevance to NZ clinical settings, and

- No cost, and/or no professional membership, instrument registration or training requirements.

\section{Instrument identification, assessment, and short-listing}

Step I: Finding and collating instruments

A comprehensive list of potentially relevant assessment instruments was identified from iterative searches of the literature following discussions between the project team and expert reference group. 


\begin{tabular}{|c|c|c|}
\hline & & Coding \\
\hline & & $\sqrt{ }=$ yes \\
\hline \multirow[t]{6}{*}{ Validity } & Face & $\sqrt{ }$ \\
\hline & Content & $\sqrt{ }$ \\
\hline & Construct & $\sqrt{ }$ \\
\hline & Comparison & $\sqrt{ }$ \\
\hline & Sensitivity & $\sqrt{ }$ \\
\hline & Factors & $\sqrt{ }$ (Number) \\
\hline \multirow[t]{5}{*}{ Reliability } & Inter-tester & $\sqrt{ }$ \\
\hline & Intra-tester & $\sqrt{ }$ \\
\hline & Test-retest & $\sqrt{ }$ \\
\hline & Internal & \\
\hline & Consistency & $\sqrt{ }$ \\
\hline $\begin{array}{l}\text { Simple instructions, short, simply } \\
\text { worded items }\end{array}$ & & $\sqrt{ }$ \\
\hline$<20$ items & & $\sqrt{ }$ (Number) \\
\hline Able to be scored manually & & $\sqrt{ }$ \\
\hline$<15$ minutes administration time & & $\begin{array}{l}\sqrt{ }(\text { Estimated } \\
\text { administration time })\end{array}$ \\
\hline Population norms & & $\sqrt{ }$ \\
\hline Cut off (threshold) scores & & $\sqrt{ }$ \\
\hline Specific to NZ & & $\sqrt{ }$ \\
\hline Instrument available at no cost & & $\sqrt{ }$ \\
\hline $\begin{array}{l}\text { Instrument available with no } \\
\text { registration/limitations }\end{array}$ & & $\sqrt{ }$ \\
\hline
\end{tabular}

Figure I Ready Reckoner developed to review persistent pain assessment measures.

\section{Step 2: Preparation for short-listing}

The Step 1 instruments were reviewed and considered for short-listing (Step 3) if they met these conditions:

- The instrument was primarily reported for assessment, rather than outcome measurement

- At least four psychometric property measures were reported in background literature (reflecting any testing for validity, reliability, sensitivity, factor analysis or comparison with other measures) ${ }^{4}$

- The instrument authors could be contacted.

\section{Step 3: Short-listing}

The purpose, psychometric properties, and clinical utility of each instrument was critically considered using the reporting 
framework ${ }^{4}$ and the Ready Reckoner. Instruments which survived Step 3 were included in the compendium.

\section{Results \\ Overview}

\section{Instrument classification}

Assessment instruments were classified into the category that best described their purpose. These classifications were largely self-reported from the background literature, and comprised pain severity, psychological, functional, or multidimensional assessment of persistent pain, and general health status/quality of life.

\section{Instrument inclusion}

Step 1 identified 116 instruments from approximately 350 publications (see row 1 of Table 1, and Appendix 2). In four instrument classification categories, sub-groups of specific instrument purpose were identified.

- For pain severity assessment, there were three sub-groups (uni-dimensional; multidimensional; neuropathic; and nonneuropathic pain discrimination).

- For psychological assessment, there were nine sub-groups (general psychological states; anxiety, depression and mood; physiological manifestations of anxiety and depression relative to persistent pain; pain cognition; catastrophizing, negative thoughts and fear; risk factor identification; pain function; coping and management; and behavioral change readiness).

- For functional assessment, there were six sub-groups (occupation focus; general function; interference [disability] in activities; impact on others; patient-specific instruments; and functional performance).

- For multidimensional assessment of persistent pain, there were seven subgroups (occupational issues; expectations; yellow flags; pain dimensions; prediction of future disability; pain profiling; outcome prediction instruments).

- No sub-groups were identified in the general health/ quality of life instruments, as all measured similar constructs.

Step 2 retained 59 instruments. Appendix 3 outlines the excluded instruments and the primary reason for exclusion. Step 3 short-listed 45 instruments. Reasons for short-listing (or excluding) instruments at this step are outlined in the 'Short-listing decisions' section of this paper.

Table 1 outlines the review consort diagram. Instrument abbreviations are expanded in Appendix 2.

\section{Psychometric properties}

There was no consistency regarding research methods or statistics for psychometric testing. This constrained development of a general picture of psychometric performance, and questioned whether one statistic was preferable to another, in demonstrating desirable characteristics of instrument performance. Table 2 reports the frequency of psychometric statistical tests, and their reported purpose, from Step 2 (considering 59 instruments).

\section{Short-listing decisions (Step 3) \\ Pain severity assessment instruments \\ Unidimensional scales}

There is considerable detail regarding the psychometric properties of pain severity scales (Visual Analog Scale [VAS]/Verbal Rating Scale [VRS]/Numeric Rating Scale [NRS])..$^{15,16}$ These instruments are useful for quick initial assessment of one pain dimension.

\section{Multidimensional pain severity assessment instruments}

The Chronic Pain Grade (CPG) scores the severity of persistent pain in three domains (characteristic pain intensity, disability, and persistence). The developmental literature (17-21 $^{17}$ provides evidence of strong psychometric properties in terms of high intra-rater reliability, internal consistency for a range of health conditions and construct validity compared to other instruments. Normative data is available.

The McGill Pain Questionnaire (Long Form) (LF-MPQ) has strong psychometric properties and normative data. ${ }^{22}$ It includes a univariate pain scale (NRS). The instructions for completing the pain adjectives section are complex and it is recommended that they should be read to patients. There are several methods of scoring, and little information as to which is most appropriate. The McGill Pain Questionnaire (Short Form) (SF-MPQ2) ${ }^{23}$ does not contain the longform body chart, and includes a VAS rather than an NRS. The short form version is less complex, quicker to administer and easier to score and interpret than the LF-MPQ. It covers the main elements of the LF-MPQ, and thus would appear to be preferable.

\section{Distinguishing between neuropathic and nonneuropathic pain}

Self-report and interview administration

The Douleur Neuropathique 4 Questions (DN4) is a 10-item instrument with high inter-rater reliability, high Kappa on retest, strong face validity and moderate correlation with health practitioners' diagnosis. ${ }^{24-26}$ An interview contributes 


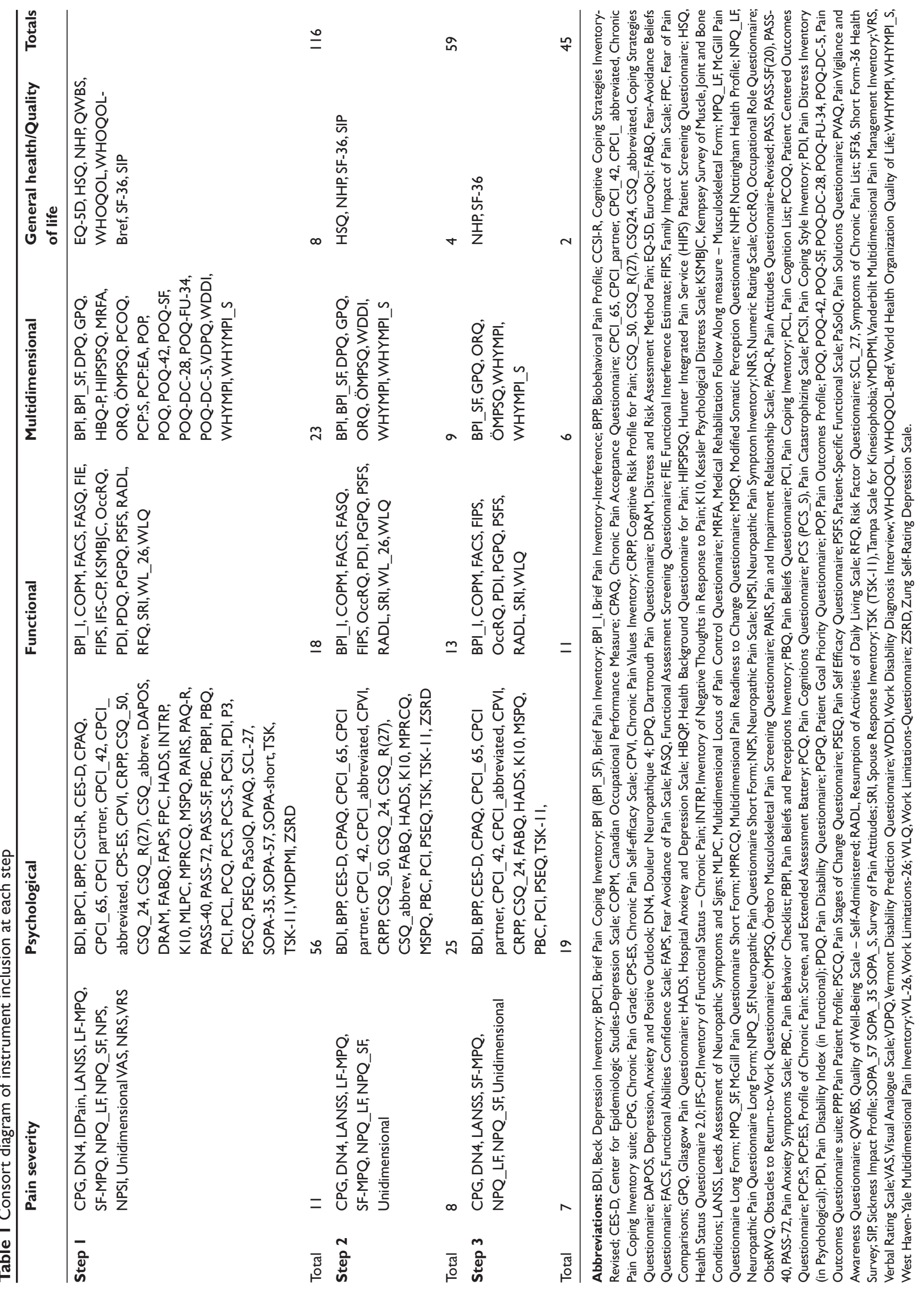


Table 2 Frequency of use, and purpose, of statistics to describe psychometric property

\begin{tabular}{|c|c|c|c|c|c|}
\hline Test & Purpose & $\%$ & Test & Purpose & $\%$ \\
\hline I. Cronbach's alpha & Internal consistency & $56.4 \%$ & 13. Face validity & & $7.3 \%$ \\
\hline 2. Student $\mathrm{t}$-test/ANOVA & Responsiveness & $38.2 \%$ & 14. Карpa & Internal consistency & $5.5 \%$ \\
\hline 3. Criterion validity & Concurrent and predictive & $32.7 \%$ & 15. Wilcoxin rank test & Responsiveness & $3.6 \%$ \\
\hline 4. Construct validity & $\begin{array}{l}\text { Convergent and divergent validity } \\
\text { OR ability to differentiate } \\
\text { between groups }\end{array}$ & $32.7 \%$ & $\begin{array}{l}\text { 16. Spearman correlation } \\
\text { coefficient }\end{array}$ & Inter-rater reliability & $1.8 \%$ \\
\hline 5. Pearson $r$ & Intra-rater reliability & $20.0 \%$ & $\begin{array}{l}\text { 17. Spearman correlation } \\
\text { coefficient }\end{array}$ & Test-retest & $1.8 \%$ \\
\hline $\begin{array}{l}\text { 6. Intra-class correlation } \\
\text { coefficient (ICC) }\end{array}$ & Intra-rater reliability & $16.4 \%$ & 18. Percent agreement & Inter-rater reliability & $1.8 \%$ \\
\hline 7. Cut point & Sensitivity and specificity & $16.4 \%$ & 19. Percent agreement & Test-retest & $1.8 \%$ \\
\hline 8. Effect size & Responsiveness & $14.5 \%$ & 20. ICC & Inter-rater reliability & $1.8 \%$ \\
\hline 9. Pearson $r$ & Test-retest & $12.7 \%$ & 2I. ICC & Internal consistency & $1.8 \%$ \\
\hline 10. Pearson $r$ & Internal consistency & $10.9 \%$ & 22. Pearson $r$ & Inter-rater reliability & $0.0 \%$ \\
\hline $\begin{array}{l}\text { II. Area under receiver operating } \\
\text { characteristic (ROC) curve }\end{array}$ & Responsiveness & $9.1 \%$ & $\begin{array}{l}\text { 23. Spearman correlation } \\
\text { coefficient }\end{array}$ & Intra-rater reliability & $0.0 \%$ \\
\hline 12. Карра & Test-retest & $7.3 \%$ & 24. Percent agreement & Intra-rater reliability & $0.0 \%$ \\
\hline
\end{tabular}

three items, using Yes/No responses, the remainder using a $0-100$ scale. This instrument is appropriate for telephone administration.

\section{Self-report and consultation administration}

The Leeds Assessment of Neuropathic Symptoms and Signs (LANSS) Pain Scale is a seven-item instrument which includes five self-report items and two sensory tests. ${ }^{27}$ The self-report questions use Yes/No responses, and the sensory testing requires the health practitioner to be with the patient for testing. Literature reports moderate Kappa test-retest scores and moderate Cronbach's alpha for internal consistency. ${ }^{27-31}$ Its cut-point of 12 is sensitive $(83 \%)$, and specific (87\%) for differentiating between neuropathic and nonneuropathic pain. ${ }^{27}$ It assesses five types of pain (thermal, dysesthesia, paroxysmal, evoked and autonomic dysfunction), and is appropriate to primary health care settings.

\section{Self-report administration}

The Neuropathic Questionnaire, Long Form (NPQ_LF) is a 12-item self-report instrument. ${ }^{32}$ The NPQ_LF has sound discriminant capacity between different pain-type groups. ${ }^{26}$ Its cut-point of 0 is reported to be moderately sensitive $(66.6 \%)$ and specific $(74.4 \%){ }^{26}$ There is a short form of three items (NPQ_SF), reported to have similar psychometric properties and discriminant capacity. ${ }^{32}$
Table 3 reports the consistently high Ready Reckoner scores for the short-listed pain severity instruments with respect to psychometric properties and clinical utility.

Category 2: Psychological pain assessment instruments The number and range of instruments in this category highlights the importance of considering the purpose, strengths and limitations of psychological assessment instruments prior to choosing the most appropriate one to use.

\section{Anxiety, depression, and mood}

The review found five relevant instruments measuring anxiety, depression and/or mood (Beck Depression Inventory [BDI], Kessler Psychological Distress Scale [K10], Hospital Anxiety and Depression Scale [HADS], Center for Epidemiologic Studies Depression Scale [CES-D], Zung Self-Rating Depression Scale [ZSRD]). Preference was given to clinically flexible, multi-construct psychological instruments relevant to persistent pain, thus ZSRD (a generic measure of depression) was excluded from further consideration.

- The BDI is a well established 21-item self-report rating inventory measuring characteristic attitudes and symptoms of depression and mood. It has high internal consistency for both psychiatric and nonpsychiatric patients. ${ }^{33}$ The BDI has comparable sensitivity and specificity with CES-D for persistent pain patients. 
Table 3 Ready Reckoner for short-listed pain severity assessment measures

\begin{tabular}{|c|c|c|c|c|c|c|c|c|}
\hline & & CPG & DN4 & LANSS & MPQ_SF & NPQ_LF & NPQ_SF & Unidimensional \\
\hline \multirow[t]{6}{*}{ Validity } & Face & $\sqrt{ }$ & & & $\sqrt{ }$ & & & $\sqrt{ }$ \\
\hline & Content & & & & $\sqrt{ }$ & & & $\sqrt{ }$ \\
\hline & Construct & $\sqrt{ }$ & & & & & & \\
\hline & Comparison & $\sqrt{ }$ & $\sqrt{ }$ & & $\sqrt{ }$ & $\sqrt{ }$ & $\sqrt{ }$ & $\sqrt{ }$ \\
\hline & Sensitivity & & $\sqrt{ }$ & & & $\sqrt{ }$ & $\sqrt{ }$ & $\sqrt{ }$ \\
\hline & Factors & 2 & 9 & 1 & 0 & 6 & 6 & I \\
\hline \multirow[t]{4}{*}{ Reliability } & Inter-tester & $\sqrt{ }$ & & & & & & \\
\hline & Intra-tester & & $\sqrt{ }$ & & & & & $\sqrt{ }$ \\
\hline & Test-retest & $\sqrt{ }$ & & $\sqrt{ }$ & $\sqrt{ }$ & $\sqrt{ }$ & $\sqrt{ }$ & $\sqrt{ }$ \\
\hline & $\begin{array}{l}\text { Internal } \\
\text { Consistency }\end{array}$ & & & $\sqrt{ }$ & & & & \\
\hline $\begin{array}{l}\text { Simple instructions, short, simply } \\
\text { worded items }\end{array}$ & & & $\sqrt{ }$ & & & $\sqrt{ }$ & $\sqrt{ }$ & $\sqrt{ }$ \\
\hline$<20$ items & & $\sqrt{ }$ & $\sqrt{ }$ & $\sqrt{ }$ & & $\sqrt{ }$ & $\sqrt{ }$ & $\sqrt{ }$ \\
\hline - Number of items & & 7 & 10 & 7 & 17 & 12 & 12 & 1 \\
\hline Able to be scored manually & & $\sqrt{ }$ & $\sqrt{ }$ & & & $\sqrt{ }$ & $\sqrt{ }$ & $\sqrt{ }$ \\
\hline$<15$ minutes administration time & & $\sqrt{ }$ & $\sqrt{ }$ & $\sqrt{ }$ & $\sqrt{ }$ & $\sqrt{ }$ & $\sqrt{ }$ & $\sqrt{ }$ \\
\hline $\begin{array}{l}\text { - Estimated average time to } \\
\text { administer }\end{array}$ & & 15 & 10 & 10 & 15 & 10 & 10 & 2 \\
\hline Norms & & $\sqrt{ }$ & & $\sqrt{ }$ & $\sqrt{ }$ & & & $\sqrt{ }$ \\
\hline Cut off scores & & $\sqrt{ }$ & $\sqrt{ }$ & $\sqrt{ }$ & $\sqrt{ }$ & $\sqrt{ }$ & $\sqrt{ }$ & \\
\hline \multicolumn{9}{|l|}{ Specific to NZ } \\
\hline No cost & & $\sqrt{ }$ & $\sqrt{ }$ & $\sqrt{ }$ & $\sqrt{ }$ & $\sqrt{ }$ & $\sqrt{ }$ & $\sqrt{ }$ \\
\hline No registration/limitations & & $\sqrt{ }$ & $\sqrt{ }$ & $\sqrt{ }$ & $\sqrt{ }$ & $\sqrt{ }$ & $\sqrt{ }$ & $\sqrt{ }$ \\
\hline Total $\sqrt{ }$ & & 12 & 10 & 8 & 9 & 10 & 10 & 13 \\
\hline
\end{tabular}

Abbreviations: CPG, Chronic Pain Grade; DN4, Douleur Neuropathique 4; LANSS, Leeds Assessment of Neuropathic Symptoms and Signs; MPQ_SF, McGill Pain Questionnaire Short Form; NPQ_LF, Neuropathic Pain Questionnaire Long Form; NPQ_SF, Neuropathic Pain Questionnaire Short Form.

- The K10 is a widely reported two-domain, 10-item measure of nonspecific psychological distress, primarily intended as a measure of mood, anxiety, and depression. ${ }^{34}$ Its developmental literature reported high sensitivity and specificity, internal consistency and intra-rater reliability. It has been used extensively in population surveys in Australia. ${ }^{35}$ The K10 is appropriate for primary health care settings, and for telephone delivery.

- The CES-D is a 20-item measure of anxiety, depression, and depressed mood symptoms, with demonstrated sensitivity and responsiveness to change. ${ }^{36}$ It has been validated in different languages. It has shorter forms (CES-D-10 (10 item), Revised Form (eight item), Iowa Form (11 item) and Boston Form (10 item), however the original CES-D is the best researched. ${ }^{37,38}$

- The HADS is a two-domain, 14-item measure designed to detect anxiety and depression, independent of somatic symptoms. ${ }^{39}$ The instrument has high internal consistency and strong correlations with quality of life measures (eg, Life Satisfaction Questionnaire). It has limited background literature for persistent pain patients. It has been validated in different languages. The HADS can only be used by psychologists with appropriate training. ${ }^{40}$

\section{Physiological manifestations of anxiety and depression} relative to persistent pain

The Modified Somatic Perception Questionnaire (MSPQ) is a 13-item measure of heightened somatic and autonomic awareness related to anxiety and depression. ${ }^{41}$ It was developed to identify clinically significant psychological distress in patients with persistent back pain. It has strong internal consistency, evidence of convergent and divergent validity with measures of anxiety and depression (eg, Minnesota Multiphasic Personality Inventory [MMPI], ZSRD, 
LF-MPQ) and significant discriminant validity within different groups of pain sufferers. ${ }^{41,42}$ It is one of the few instruments linking physical and psychological symptoms and thus adds important information to persistent pain assessments. It uses short wording which is appropriate for primary health care settings and telephone delivery.

\section{Pain cognition and risk factor identification}

No instrument was retained for short-listing.

\section{Catastrophizing, negative thoughts, fear}

Three instruments were retained for short-listing.

- The Fear Avoidance Beliefs Questionnaire (FABQ) is a 16-item, short-worded, work-focused measure of patients' beliefs about how physical activity and work affect their pain. ${ }^{43,44}$ The FABQ developmental literature reports high intra-tester reliability and test-retest, high internal consistency, and sound criterion and construct validity, tested against work time lost in the last 12 months, self-reported disability and poor behavioral performance. The FABQ is moderately correlated with the MSPQ, and highly correlated with the Tampa Scale for Kinesiophobia (TSK-11). ${ }^{43}$ It is appropriate for primary health care settings and telephone delivery.

- The TSK is available in long (17 items) and short (11 items) versions. Both instruments have similar high intra-rater reliability and internal consistency, and are sensitive to differences between patients, and interventions. ${ }^{45}$ The shorter version (TSK-11) is more relevant for primary health care assessment, and for telephone administration. The TSK has been validated in other languages.

- The Pain Distress Inventory (PDI) measures pain-related interference with role functioning, using domains of family/home responsibilities, recreation, social activity, occupation, sexual behavior, self-care and life-support activity. ${ }^{46}$ It has sound internal consistency and content validity, and is sensitive to responses from different patient sub-groups. It correlates strongly with the Oswestry Disability Index and moderately with the BDI. The PDI is relevant to primary and secondary settings.

\section{Behavioral change readiness}

Four instruments were retained in this sub-group.

The Pain Behavior Checklist (PBC) is a 49-item, short-worded self-report about behaviors related to pain, assessing avoidance, complaint, and help-seeking. ${ }^{47}$ The PBC has moderate evidence of intra-rater reliability, low correlations with measures of depression, good discriminant validity between different types of headache sufferers, and low correlations with measures of noise sensitivity. ${ }^{47}$ Population norms reflect 1. 5 standard deviations around the mean. ${ }^{47,48}$

The Chronic Pain Values Inventory (CPVI) is a patientcentered six-domain instrument assessing family, intimate relations, friends, work, health, and growth or learning. ${ }^{49}$ The CPVI is based on a values-based cognitive-behavioral approach to assessing persistent pain. The developmental literature reports strong correlations with other pain measures (Pain Anxiety Symptoms Scale [PASS], Chronic Pain Acceptance Questionnaire [CPAQ], work capacity, and medications), and significant discriminant abilities. ${ }^{49}$ This instrument evaluates the discrepancy between importance and success in patient values related to functioning in different environments (family, intimate relations, friends, work, health and growth and learning).

The Multidimensional Pain Readiness to Change Questionnaire (MPRCQ) scored highly on psychometric properties (convergent and discriminant validity, intra-rater reliability and internal consistency). However, the authors advised that at present, this instrument was available only for research purposes. ${ }^{50}$ It was thus excluded from further consideration for the compendium.

The Pain Self-Efficacy Questionnaire (PSEQ) is a 10-item short-worded instrument which measures self-confidence in performing functional and social activities, despite the presence of pain. ${ }^{51}$ The PSEQ is relevant to assess pain cognition in primary health care settings and can be administered by telephone. It has high intra-rater reliability, internal consistency and stability over retest.

\section{Pain function, coping and management}

Twelve instruments (six sets of instruments) were shortlisted. Three measured persistent pain coping (Chronic Pain Coping Inventory [CPCI] suite of four instruments, Coping Strategies Questionnaire [CSQ] suite of four instruments, and the Pain Coping Inventory [PCI]). The other instruments comprised the CPAQ which measures acceptance of persistent pain, the Cognitive Risk Profile for Pain (CRPP) which considers persistent pain management beliefs, and the Biobehavioral Pain Profile (BPP) which measures reactions to persistent pain.

The CPCI suite (CPCI_65 [original], CPCI_partner, CPCI_42, CPCI_abbreviated) measures persistent pain coping strategies. ${ }^{52-54}$ The original CPCI includes domains of guarding, resting, asking for assistance, relaxation, task persistence, exercise/stretch, seek support, and 
coping self-statements. All versions of the CPCI demonstrate moderate to high internal consistency, and strong evidence of convergent, divergent and criterion validity tested withininstrument domains, and with other instruments (eg, CES-D and Numerical Pain Rating Scale [NRS]). An advantage of this instrument is its 'partner' version, and the shorter versions which may be used for primary care assessment, or for retest. The instruments have relatively complex wording which may not be appropriate for people of low literacy. The instrument has been validated in other languages.

The CSQ suite assesses persistent pain coping. ${ }^{55,56}$ It contains a long form (CSQ_LF of 50 items), a revised form (CSQ_R of 27 items) and an abbreviated 24 item form (CSQ-24). All forms have similarly strong internal consistency, and strong concurrent and divergent validity with VAS and HADS. The CSQ_LF and the CSQ_R are wordy, thus they may not be suitable for some persistent pain patients with low literacy. Scoring instructions are published for the abbreviated version, which appeared most appropriate for clinical use.

The PCI is a multi-domain, simply-worded 33-item instrument which measures active and passive pain coping strategies using specific cognitive and behavioral strategies (pain transformation, distraction, reducing demands, retreating, worrying, and resting) ${ }^{57}$ It has moderate intra-rater reliability and internal consistency, strong inter-domain correlation, and varying degrees of convergent and discriminant validity when compared with VAS, age, and illness states.

The CPAQ is a 20-item measure of pain acceptance. ${ }^{59}$ It has two domains that measure activity engagement (pursuit of life activities regardless of pain) and pain willingness (recognition that avoidance and control are often unworkable methods of dealing with persistent pain). Acceptance of persistent pain is believed to allow patients to focus on engaging in meaningful and valued activities and goals. The CPAQ demonstrates moderate internal consistency, and divergent validity with the BDI. ${ }^{59}$ This instrument uses wordy items which may not be suitable for self-report from patients with low literacy.

\section{Persistent pain management beliefs}

Persistent pain management beliefs could be measured by the nine domain instrument CRPP, or the BPP.

The CRPP is a commercially available instrument which explores beliefs and attitudes that could interfere with pain management. ${ }^{60}$ The CRPP domains deal with philosophic beliefs about pain, denial that mood affects pain, denial that pain affects mood, perception of blame, inadequate support, disability entitlement, desire for medical breakthrough, scepticism of multidisciplinary approach and conviction of hopelessness. It has high internal consistency, and divergent validity with the PDI, CSQ, and MPQ.

The BPP is a composite measure of behavioral, physiological, and cognitive reactions to pain. ${ }^{61}$ It has six domains of health care avoidance, physiological responsivity, thoughts of disease progression, environmental influences, past and current treatment, and loss of control. The initial intent of the instrument was to use each patient's answers to create a profile that predicts what nondrug methods might work best for managing pain. In the developmental literature the BPP showed poor intra-rater reliability, high internal consistency, and divergent validity with the BDI and body consciousness. ${ }^{61}$ This instrument appears worded for patients of usual literacy levels.

Table 4 provides the Ready Reckoner scores for short-listed psychological persistent pain assessment instruments, and highlights their variable quality in terms of psychometric properties and clinical utility.

\section{Category 3: Functional performance assessment instruments}

A range of instruments which purported to measure function in persistent pain patients were considered for short-listing.

\section{Instrument redundancy}

The Work Limitations Questionnaire (WLQ) and the Work Limitations-26 (WL-26) were developed by the same group of researchers, and share over $90 \%$ items and wording. ${ }^{62,63}$ The WLQ is a 25-item measure of on-the-job impact of persistent health problems and/or treatment on work limitations (measuring capacity to work whilst workers are at work). The WLQ has four demand domains: physical, time, mentalinterpersonal and output. It has been tested using a two and four-week recall period. It scores each item using a five-point Likert Scale: $0 \%$, health makes the job demand difficult none of the time; $25 \%$, a little of the time; $50 \%$, some of the time; $75 \%$, a great deal of the time; and $100 \%$, health makes the job demand difficult all of the time. The WLQ correlates well with adverse events in the workplace such as employee injuries and sick leave. The instrument has high internal consistency and moderate criterion and construct validity with the Short Form Health-36 Survey Questionnaire (SF-36). It is useful for selfreporting. The WL-26 has 26-items of similar style, purpose and scoring to the WLQ. It defines the middle category on the Likert scale differently, as 'approximately half the time'. Contact with the authors indicated that either instrument could be used to assess limitations in work functioning, however, they recommended the WLQ as the more robust measure. Both instruments require registration prior to use. 


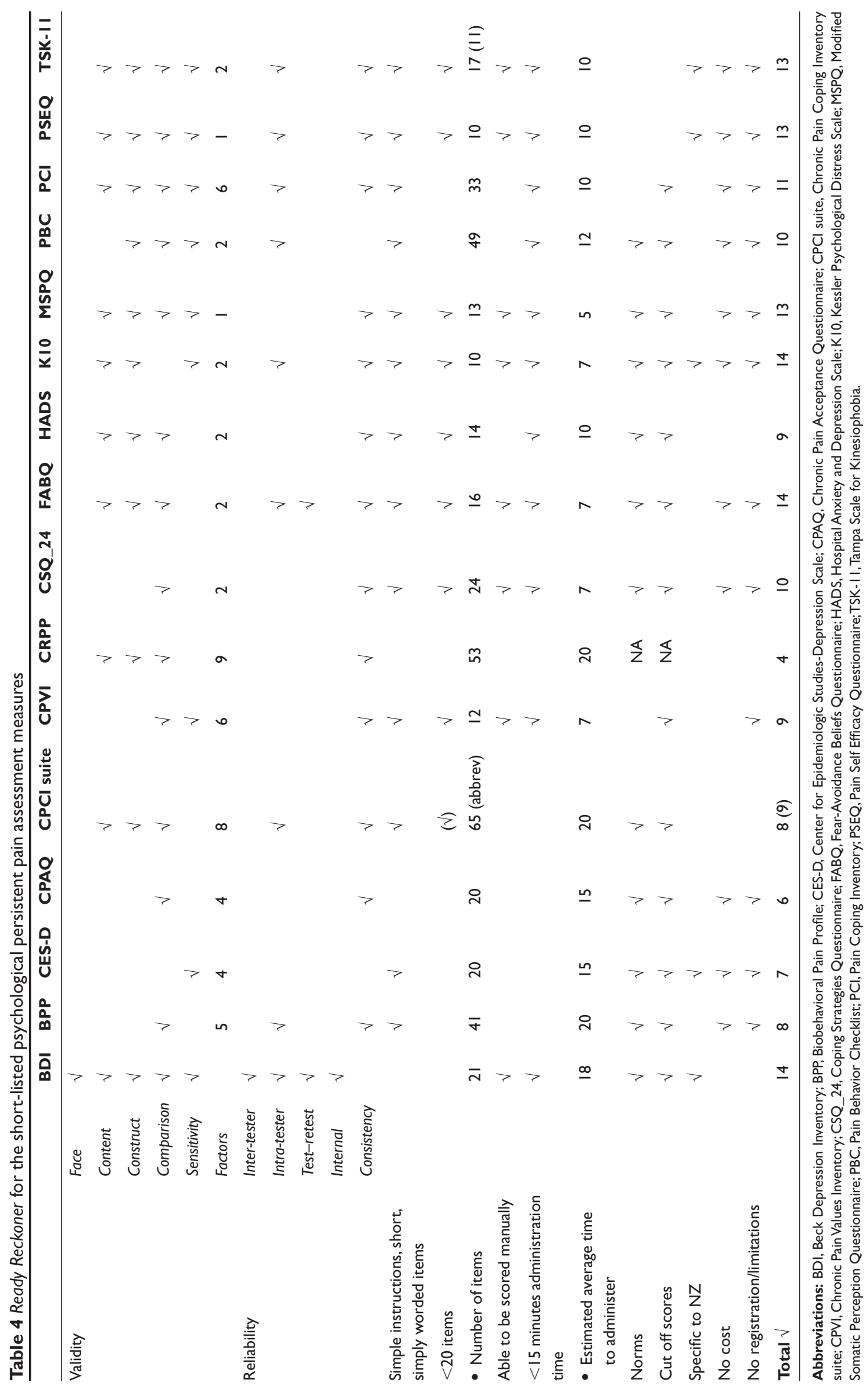




\section{Occupation focus}

Two instruments (WLQ and Occupational Role Questionnaire [OccRQ]) were identified, measuring different aspects of occupation. The OccRQ is an eight-item, two-domain instrument which tests attitudes to returning/remaining at work. ${ }^{64}$ It has two domains, assessing productivity and satisfaction. This instrument is suitable for self-report and administration in primary health care settings. The OccRQ has strong evidence of test-retest reliability and high internal consistency. It is moderately correlated with pain intensity (VAS).

\section{General function}

Three instruments were measures of general function, relevant in both primary and secondary health care settings: the 15-item Functional Abilities Confidence Scale (FACS), the 12-item Resumption of Activities of Daily Living (RADL) scale and the seven-item PDI.

The FACS measures confidence with general functional activities related to movements and postures affected by low back pain. ${ }^{65}$ The RADL measures self-reported resumption of usual daily activities estimating confidence regarding return to usual activities. ${ }^{66}$ These instruments were developed by the same research group, are strongly correlated, and have high internal consistency.

The PDI estimates impact on everyday activities and relationships ${ }^{67}$ It is a measure of pain-related interference with role functioning, in domains of family/home responsibilities, recreation, social activity, occupation, sexual behavior, self-care and life-support activity. It is sensitive to responses from different patient groups, and correlates moderately with the BDI.

\section{Patient-specific instruments}

The importance of considering the patient's perspective when measuring function was highlighted by Kliempt and colleagues. ${ }^{68}$ Two patient-specific instruments were identified, both with strong psychometric properties and tested across health conditions.

The Patient Goal Priority Questionnaire (PGPQ) is a patient-specific measure of patients' behavioral goals. ${ }^{69}$ There are three measures: a questionnaire for assessing goals at baseline, a follow-up questionnaire, and a questionnaire for priority revision that can be used at any time after the commencement of treatment. The PGPQ can be used to identify and assess behavioral treatment goals, elaborate individual functional behavioral analyses relevant for everyday life functioning and determine the clinical significance of treatment. It is negatively and moderately correlated with the PDI, and is not intended for group analyses.

The Patient-Specific Functional Scale (PSFS) is a patient-specific clinical tool for eliciting, measuring and recording patients' descriptions of their disabilities..$^{70}$ It has strong evidence of construct validity, intra-rater reliability, sensitivity and specificity, and has an estimated amount of clinically significant change. ${ }^{71,72}$

\section{Interference (disability) in functional activities}

Two instruments measured the extent of interference in usual function (measures of disability); the Functional Assessment Screening Questionnaire (FASQ) and the Brief Pain Inventory-Interference (BPI_I).

The FASQ is a simply-worded 15 -item instrument. ${ }^{73}$ It had reports of high internal consistency, good ability to differentiate between pain subgroups, and moderate divergence with pain intensity (VAS). No contact could be made with the developer, thus this instrument was excluded from consideration.

The BPI_I is a 7-item derivative of BPI_long form (BPI_LF), which is considered in the next section. ${ }^{74}$ The BPI_I measures interference in general activity, sleep, mood, and relationships. It can be quickly self- or interviewer-administered and is validated in other languages. Its wording may challenge patients of low-literacy. It has high internal consistency and moderate discriminant validity. The BPI_I has been modified into a 12-item instrument, adding items relevant to disability (self care, recreation, social activities, finding out information and communication). ${ }^{75}$ The BPI suite requires registration prior to use.

\section{Impact on others}

Two instruments assessed the influence of pain, and people close to the patient. One instrument assessed the impact of the patient's pain on others (Family Impact of Pain Scale [FIPS]), and the other assessed the impact of the spouse ('significant other') on a patient's pain responses (Spouse Response Inventory [SRI]).

The FIPS is a 10-item instrument measuring the extent to which family activities and interactions are affected by the patient's persistent pain. ${ }^{76}$ It has two domains showing moderate test-retest and internal consistency. It is sensitive in identifying patients whose behavior significantly impacts on family members. It moderately correlates with the VAS, the BDI, and the CSQ.

The SRI assesses the extent to which spouse responses contribute to a patient's pain and disability. ${ }^{77}$ It has four 
domains (solicitous and negative spouse response pain behaviors, and facilitating and negative spouse response well behaviors). It has moderate intra-rater reliability and poor to moderate construct validity with several other instruments (eg, PBC, VAS, BDI). The SRI requires registration with the author prior to use.

\section{Functional performance}

The Canadian Occupational Performance Measure (COPM) is a patient-centered measure of performance of activities and tasks of daily living. ${ }^{78-82}$ It is a semi-structured interview in which patients identify and rate areas of difficulty in occupational performance. It is a broad-ranging comprehensive instrument with strong evidence of construct and content validity, reliability in administration, test-retest, and correlation with other performance measures. It is a commercial product designed to be used by registered occupational therapists.
Table 5 reports the Ready Reckoner for the functional pain assessment instruments, highlighting their variable psychometric properties and clinical utility.

\section{Category 4: Multidimensional pain assessment instruments \\ Exclusions}

Two instruments were excluded on grounds of redundancy. The Dartmouth Pain Questionnaire (DPQ) is a five-domain instrument adjunctive to the MPQ. It assesses the impact of pain on function. ${ }^{83}$ Other instruments measure this construct more comprehensively (eg, BPI). The BPI (32 items) and BPI_SF (15 items) are multidimensional psychometrically-sound measures of persistent pain features including pain severity, impact of pain on daily function, location of pain, pain medications and amount of pain relief in the past 24 hours or past week. ${ }^{74}$ The BPI has been validated in several languages. There is significant overlap between

Table 5 Ready Reckoner for the short-listed functional persistent pain assessment measures

\begin{tabular}{|c|c|c|c|c|c|c|c|c|c|c|c|c|}
\hline & & BPI_I & COPM & FACS & FIPS & OccRQ & PDI & PGPQ & PSFS & RADL & SRI & WLQ \\
\hline \multirow[t]{6}{*}{ Validity } & Face & $\sqrt{ }$ & $\sqrt{ }$ & & & $\sqrt{ }$ & & & & & & \\
\hline & Content & & $\sqrt{ }$ & & $\sqrt{ }$ & & & $\sqrt{ }$ & & & & \\
\hline & Construct & & $\sqrt{ }$ & $\sqrt{ }$ & $\sqrt{ }$ & & $\sqrt{ }$ & $\sqrt{ }$ & $\sqrt{ }$ & & $\sqrt{ }$ & $\sqrt{ }$ \\
\hline & Comparison & & $\sqrt{ }$ & $\sqrt{ }$ & $\sqrt{ }$ & $\sqrt{ }$ & $\sqrt{ }$ & $\sqrt{ }$ & $\sqrt{ }$ & $\sqrt{ }$ & $\sqrt{ }$ & $\sqrt{ }$ \\
\hline & Sensitivity & $\sqrt{ }$ & $\sqrt{ }$ & $\sqrt{ }$ & $\sqrt{ }$ & $\sqrt{ }$ & $\sqrt{ }$ & $\sqrt{ }$ & $\sqrt{ }$ & $\sqrt{ }$ & & \\
\hline & Factors & 1 & & 2 & 2 & 2 & 2 & & & 5 & 4 & \\
\hline \multirow[t]{5}{*}{ Reliability } & Inter-tester & & $\sqrt{ }$ & & & & & $\sqrt{ }$ & & & & \\
\hline & Intra-tester & & $\sqrt{ }$ & $\sqrt{ }$ & & $\sqrt{ }$ & & & $\sqrt{ }$ & $\sqrt{ }$ & $\sqrt{ }$ & \\
\hline & Test-retest & & $\sqrt{ }$ & $\sqrt{ }$ & $\sqrt{ }$ & $\sqrt{ }$ & & & & & & $\sqrt{ }$ \\
\hline & Internal & & & & & & & & & & & \\
\hline & Consistency & $\sqrt{ }$ & & $\sqrt{ }$ & $\sqrt{ }$ & $\sqrt{ }$ & $\sqrt{ }$ & & & $\sqrt{ }$ & & $\sqrt{ }$ \\
\hline $\begin{array}{l}\text { Simple instructions, short, simply } \\
\text { worded items }\end{array}$ & & $\sqrt{ }$ & & $\sqrt{ }$ & $\sqrt{ }$ & $\sqrt{ }$ & & & $\sqrt{ }$ & $\sqrt{ }$ & $\sqrt{ }$ & $\sqrt{ }$ \\
\hline$<20$ items & & & & $\sqrt{ }$ & $\sqrt{ }$ & $\sqrt{ }$ & $\sqrt{ }$ & & $\sqrt{ }$ & $\sqrt{ }$ & & \\
\hline - Number of items & & 7 & & 15 & 10 & 8 & 7 & 22 & 3 & 12 & 39 & 25 \\
\hline Able to be scored manually & & $\sqrt{ }$ & & & $\sqrt{ }$ & $\sqrt{ }$ & $\sqrt{ }$ & $\sqrt{ }$ & $\sqrt{ }$ & $\sqrt{ }$ & & $\sqrt{ }$ \\
\hline$<15$ minutes administration time & & $\sqrt{ }$ & & $\sqrt{ }$ & $\sqrt{ }$ & $\sqrt{ }$ & $\sqrt{ }$ & $\sqrt{ }$ & $\sqrt{ }$ & $\sqrt{ }$ & & $\sqrt{ }$ \\
\hline - Estimated average time to administer & & 5 & & 10 & 10 & 5 & 7 & 15 & 5 & 7 & 20 & 15 \\
\hline Norms & & & $\sqrt{ }$ & & & $\sqrt{ }$ & $\sqrt{ }$ & NA & NA & & & $\sqrt{ }$ \\
\hline Cut off scores & & $\sqrt{ }$ & $\sqrt{ }$ & $\sqrt{ }$ & $\sqrt{ }$ & & $\sqrt{ }$ & NA & NA & $\sqrt{ }$ & & $\sqrt{ }$ \\
\hline \multicolumn{13}{|l|}{ Specific to NZ } \\
\hline No cost & & $\sqrt{ }$ & & $\sqrt{ }$ & $\sqrt{ }$ & $\sqrt{ }$ & $\sqrt{ }$ & $\sqrt{ }$ & $\sqrt{ }$ & $\sqrt{ }$ & $\sqrt{ }$ & $\sqrt{ }$ \\
\hline No registration/limitations & & & & $\sqrt{ }$ & $\sqrt{ }$ & $\sqrt{ }$ & $\sqrt{ }$ & $\sqrt{ }$ & $\sqrt{ }$ & $\sqrt{ }$ & & \\
\hline Total $\sqrt{ }$ & & 8 & 10 & 12 & 13 & 13 & II & 9 & 10 & 11 & 5 & 10 \\
\hline
\end{tabular}

Abbreviations: BPI_I, Brief Pain Inventory-Interference; COPM, Canadian Occupational Performance Measure; FACS, Functional Abilities Confidence Scale; FIPS, Family Impact of Pain Scale; OccRQ, Occupational Role Questionnaire; PDI, Pain Distress Inventory; PGPQ, Patient Goal Priority Questionnaire; PSFS, Patient-Specific Functional Scale; RADL, Resumption of Activities of Daily Living Scale; SRI, Spouse Response Inventory; WLQ, Work Limitations-Questionnaire. 
BPI and BPI_SF items, and therefore the BPI_SF was short-listed. The BPI suite is free to use after registration.

The Work Disability Diagnosis Interview (WDDI) was excluded on the basis of complexity and administration time. It includes several standard assessment instruments, a physical examination and an interview. ${ }^{84}$ Its estimated completion time exceeds three hours, constraining its utility in most clinical settings. This instrument however offers a comprehensive approach to persistent pain assessment, and may be useful in multidimensional multidisciplinary specialized assessment settings.

\section{Retained instruments}

The Obstacles to Return-to-work Questionnaire (ObsRWQ) measures prognosis for return to work, pain intensity and depression. ${ }^{85}$ It is moderately sensitive and specific around a cut-point of 150. Part I assesses depression and pain intensity; Part II assesses six domains of difficulties at work return, physical workload and harmfulness, social support at work, worry due to sick leave, work satisfaction, and family situation and support; and Part III is a single scale dealing with perceived prognosis of work return. The items in Part I and some of the items in Part III are taken from the Örebro Musculoskeletal Pain Screening Questionnaire (ÖMPSQ). This instrument correlates moderately with BDI.

The ÖMPSQ, if applied 4-12 weeks after injury, identifies the likelihood that workers with soft tissue injury will develop long-term disability. ${ }^{86}$ This provides an early opportunity to intervene to reduce the risk of long term disability in injured workers. Specific to low back pain, the instrument has been tested in several settings, providing thresholds for predicting risk of long-term disability with moderate evidence of validity. ${ }^{87-90}$

The West Haven-Yale Multidimensional Pain Inventory (WHYMPI) is a two-instrument suite (patient and 'significant other' versions). The patient version has 52 items in 12 domains divided into three parts, evaluating perceived interference of pain in occupational, social and family functioning; perceptions of responses of others to the patient's pain, and participation in common daily activities. ${ }^{91}$ There are extensive norms, and strong psychometric properties. The 'significant other' version (WHYMPI_S) evaluates the influence of the patients' pain on the partner/spouse, and partner influence on the patient. ${ }^{92}$ The WHYMPI requires registration prior to use.

Table 6 provides the Ready Reckoner for multidimensional pain assessment instruments. The generally high scores for these instruments indicate their value for health practitioners, in using one instrument to assess a number of constructs related to persistent pain.

\section{Category 5: Quality of life/general health assessment instruments}

A number of instruments were identified in this category, with different purposes in persistent pain assessment.

\section{Exclusions}

The EuroQol (EQ-5D), World Health Organization Quality of Life (WHOQOL; WHOQOL-Bref) and Quality of Well Being Scale (QWBS) instruments were developed specifically for population-health research and clinical trials. ${ }^{93-95}$ They were not intended for clinical application, and were thus excluded from further consideration.

The remaining instruments are all commercial, and could be used for clinical assessments. Prior to the development of the SF-36, the Sickness Impact Profile (SIP) was the best available quality-of-life measure. ${ }^{96}$ It assesses sleep and rest, eating, work, home management, recreation and pastimes, ambulation, mobility, body care and movement, social interaction, alertness behavior and communication. These domains can be aggregated into broader physical and psychosocial domains. As it has now largely been superseded by the SF-36, the SIP was excluded from consideration. The Health Status Questionnaire (HSQ 2.0) contains the same items and domains as the SF-36, relevant to persistent pain. ${ }^{97}$ Given the lack of normative data, and overlap with the SF-36, the HSQ was also excluded from further consideration.

\section{Retained instruments}

The SF-36 contains eight domains (physical functioning, role limitations due to physical problems, bodily pain, social functioning, mental health, role limitations due to emotional problems, vitality, and overall/general health). ${ }^{98}$ International population and health condition norms are reported. ${ }^{99}$ Given its normative data, the large number of publications which report use of the SF-36, and its wide use in clinical and research environments, it was short-listed.

The Nottingham Health Profile (NHP) measures pain intensity, and impact of pain on general life areas. ${ }^{100}$ It has strong evidence of reliability, validity, sensitivity to change and domain construction (physical activities, pain, sleep, social isolation, emotional reactions, energy level, and whether their present level of health affects their life in occupation, personal relationships, hobbies etc). In a publication which compared the NHP and SF-36 for patients with lower limb ischaemia, ${ }^{101}$ the NHP was more sensitive in discriminating between ischemia levels. This highlights the 
Table 6 Ready Reckoner for the short-listed multidimensional persistent pain assessment measures

\begin{tabular}{|c|c|c|c|c|c|c|c|}
\hline & & BPI_SF* & GPQ & OccRQ & ÖMPSQ & WHYMPI & WHYMPI_S \\
\hline \multirow[t]{6}{*}{ Validity } & Face & $\sqrt{ }$ & $\sqrt{ }$ & $\sqrt{ }$ & $\sqrt{ }$ & $\sqrt{ }$ & $\sqrt{ }$ \\
\hline & Content & $\sqrt{ }$ & & & $\sqrt{ }$ & & \\
\hline & Construct & $\sqrt{ }$ & $\sqrt{ }$ & $\sqrt{ }$ & $\sqrt{ }$ & $\sqrt{ }$ & $\sqrt{ }$ \\
\hline & Comparison & & $\sqrt{ }$ & $\sqrt{ }$ & & $\sqrt{ }$ & $\sqrt{ }$ \\
\hline & Sensitivity & $\sqrt{ }$ & $\sqrt{ }$ & $\sqrt{ }$ & $\sqrt{ }$ & $\sqrt{ }$ & $\sqrt{ }$ \\
\hline & Factors & 2 & 5 & 9 & & 3 & 3 \\
\hline \multirow[t]{5}{*}{ Reliability } & Inter-tester & $\sqrt{ }$ & $\sqrt{ }$ & & $\sqrt{ }$ & & \\
\hline & Intra-tester & $\sqrt{ }$ & & $\sqrt{ }$ & & $\sqrt{ }$ & $\sqrt{ }$ \\
\hline & Test-retest & $\sqrt{ }$ & $\sqrt{ }$ & & $\sqrt{ }$ & $\sqrt{ }$ & $\sqrt{ }$ \\
\hline & Internal & & & & $\sqrt{ }$ & & \\
\hline & Consistency & $\sqrt{ }$ & $\sqrt{ }$ & $\sqrt{ }$ & & $\sqrt{ }$ & $\sqrt{ }$ \\
\hline Simple instructions, short, simply worded items & & $\sqrt{ }$ & $\sqrt{ }$ & $\sqrt{ }$ & $\sqrt{ }$ & $\sqrt{ }$ & $\sqrt{ }$ \\
\hline$<20$ items & & $\sqrt{ }$ & & & & & \\
\hline - Number of items & & 15 & 24 & 55 & 56 & 52 & 52 \\
\hline Able to be scored manually & & $\sqrt{ }$ & & $\sqrt{ }$ & $\sqrt{ }$ & $\sqrt{ }$ & $\sqrt{ }$ \\
\hline$<15$ minutes administration time & & $\sqrt{ }$ & $\sqrt{ }$ & & & & \\
\hline - Estimated average time to administer & & 10 & 12 & 20 & 20 & 20 & 20 \\
\hline Norms & & & & $\sqrt{ }$ & $\sqrt{ }$ & $\sqrt{ }$ & $\sqrt{ }$ \\
\hline Cut off scores & & $\sqrt{ }$ & $\sqrt{ }$ & $\sqrt{ }$ & $\sqrt{ }$ & $\sqrt{ }$ & $\sqrt{ }$ \\
\hline Specific to NZ & & & & & $\sqrt{ }$ & & \\
\hline No cost & & $\sqrt{ }$ & $\sqrt{ }$ & $\sqrt{ }$ & $\sqrt{ }$ & $\sqrt{ }$ & $\sqrt{ }$ \\
\hline No registration/limitations & & & $\sqrt{ }$ & $\sqrt{ }$ & $\sqrt{ }$ & $\sqrt{ }$ & $\sqrt{ }$ \\
\hline Total $\sqrt{ }$ & & 14 & 12 & 12 & 14 & 13 & 13 \\
\hline
\end{tabular}

Abbreviations: BPI_SF, Brief Pain Inventory; GPQ, Glasgow Pain Questionnaire; OccRQ, Occupational Role Questionnaire; ÖMPSQ, Örebro Musculoskeletal Pain Screening Questionnaire; WHYMPI,WHYMPI_S, West Haven-Yale Multidimensional Pain Inventory.

importance of considering the sensitivity of any instrument for patients with different types of persistent pain.

Table 7 provides the Ready Reckoner scores for the general health/quality of life assessment instruments.

\section{Discussion}

This review identified many assessment instruments published over the past 20 years, dealing with many constructs related to persistent pain presentations and behaviors. Only a few instruments were specific to single health disciplines, or single persistent pain constructs. The publication of assessment instruments appears to mirror developments in understanding persistent pain behaviors and presentations, in terms of neuroanatomy, biology, physiology, psychology, and social science. ${ }^{5-14}$ However, no one instrument currently appears to assess all features of persistent pain, and thus multiple instruments are required to provide a comprehensive description of an individual with persistent pain. This is perhaps not surprising, as given the variability in etiology, location and nature of persistent pain presentations, and the variable individual time taken for such pain to develop, it would be a challenge to develop one instrument which addressed all aspects of persistent pain for all patients. ${ }^{6-10}$ Given the time required to administer even the shortest instrument in every assessment category identified in this review, this could be daunting and burdensome for patients and health providers. Thus, health practitioners using persistent pain assessment instruments for the first time would be advised to start with a multidimensional instrument which provides an overview of the patient. Once core areas of concern have been identified, more specific assessment instruments could be used.

There was considerable overlap in item intent and wording within- and between-persistent pain assessment categories in the short-listed instruments. It appears that instruments measuring similar constructs have been developed by different research groups with apparently little reflection on already published instruments. Choosing between similarly worded and constructed instruments with similar purposes, and similar psychometric properties, thus provides a challenge for health practitioners. The review 
Table 7 Ready Reckoner for the short-listed general health/quality of life persistent pain assessment measures

\begin{tabular}{|c|c|c|c|}
\hline & & NHP & SF-36 \\
\hline \multirow[t]{6}{*}{ Validity } & Face & $\sqrt{ }$ & $\sqrt{ }$ \\
\hline & Content & $\sqrt{ }$ & $\sqrt{ }$ \\
\hline & Construct & $\sqrt{ }$ & $\sqrt{ }$ \\
\hline & Comparison & $\sqrt{ }$ & $\sqrt{ }$ \\
\hline & Sensitivity & $\sqrt{ }$ & $\sqrt{ }$ \\
\hline & Factors & 5 & 9 \\
\hline \multirow[t]{5}{*}{ Reliability } & Inter-tester & $\sqrt{ }$ & $\sqrt{ }$ \\
\hline & Intra-tester & $\sqrt{ }$ & $\sqrt{ }$ \\
\hline & Test-retest & $\sqrt{ }$ & $\sqrt{ }$ \\
\hline & Internal & & \\
\hline & Consistency & $\sqrt{ }$ & $\sqrt{ }$ \\
\hline $\begin{array}{l}\text { Simple instructions, short, simply } \\
\text { worded items }\end{array}$ & & $\sqrt{ }$ & $\sqrt{ }$ \\
\hline$<20$ items & & & \\
\hline Number of items & & 38 & 36 \\
\hline \multicolumn{4}{|l|}{ Able to be scored manually } \\
\hline$<15$ minutes administration time & & $\sqrt{ }$ & \\
\hline Estimated average time to administer & & 10 & 20 \\
\hline Norms & & $\sqrt{ }$ & $\sqrt{ }$ \\
\hline \multicolumn{4}{|l|}{ Cut off scores } \\
\hline Specific to NZ & & & $\sqrt{ }$ \\
\hline \multicolumn{4}{|l|}{ No cost } \\
\hline \multicolumn{4}{|l|}{ No registration/limitations } \\
\hline Total score & & 12 & 12 \\
\hline
\end{tabular}

Abbreviations: NHP, Nothngham Health Profile; SF-36, Short Form Health Survey-36.

highlighted how some instruments changed over time, with little explanation of wording change, change in item order, or addition or removal of items. This suggests an opportunity for international research groups to collaborate on collating, critically appraising and then distilling essential items from key instruments, in order to develop a comprehensive battery of assessment questions which would address all aspects of persistent pain presentation.

The generalizability of many instruments was constrained by the size of study samples, and/or the specific nature of populations on which instruments were tested. This reduced the usefulness of many instrument's population norms, or cut-points, and raised concerns that if these were inappropriately applied, patients may be inaccurately classified regarding persistent pain behaviors. This highlights the need for instrument developers to research their instrument's performance in different patient subgroups, with different demographic characteristics and health conditions.
This review also flagged the importance of improved understanding of the social and cultural implications of describing pain experiences, to test the stability and generalizability of persistent pain descriptors across population groups and settings.

There was little consistency in choices of statistics tests for psychometric properties, or ways in which psychometric properties were reported. This meant that, despite the volume of published research in this area, little information was presented in useful terms to encourage clinical uptake of any persistent pain assessment instrument. Thus for many health practitioners, the wealth and variability of published material on persistent pain assessment may be overwhelming with respect to instrument choice. For instance, there was little convincing evidence to support the use of many long versus short/revised instruments, in terms of psychometric properties. Choice would appear to be based on personal preference, and/ or clinical imperatives. This finding highlights the need for developers of new instruments to justify item intent, number, and wording, and to provide evidence of psychometric properties to convince users that their instrument provides the most useful assessment information in specific circumstances.

Fewer than $25 \%$ of instruments initially identified in the literature search were short-listed. The short-listing process relied on the quality of background literature reporting. Had more detail been available on psychometric properties or clinical utility, other instruments may have been short-listed. Some instruments, whilst appearing promising, reported psychometric properties in unpublished conference proceedings or research theses. As these were often not available via library databases, the instrument was excluded in line with the review criteria. Some instruments showed promise on initial test results published in one or two research papers, however there was little subsequent research to support its use. On the other hand, some instruments with less robust psychometric properties were regularly reported as research tools, and would be thus more familiar to health practitioners. Most instrument developers could be contacted, and many willingly provided additional (although often unpublished) details on their instrument's performance.

The Ready Reckoner, although unvalidated, provided a comprehensive way of collating key information on psychometric properties and clinical utility for efficient clinical decision-making. It highlighted that many instruments did not have good clinical utility despite having sound psychometric properties. Clinical utility could be constrained by lengthy or unwieldy questions, complex wording, or multiple intentions in one question. Administration time for such instruments 
often precluded their ready clinical use. This review sought to identify instruments relevant to primary health care settings. These were generally short, efficient to deliver and score and sensitive to persistent pain problems. A resource of high quality instruments for primary care providers should increase the frequency with which persistent pain patients are identified early.

The importance of considering the patient in an holistic manner was supported not only by the different categories of persistent pain assessment, but also by the availability of assessment instruments for 'significant others'. These instruments recognize that patients with persistent pain rarely exist in isolation, and that their pain behaviors have an effect on, and are influenced by, the behaviors of people around them.

\section{Conclusion}

Early identification of patients at-risk of developing persistent pain is essential to ensure appropriate and timely intervention, and reduce avoidable individual, social, community and work-related costs. No one assessment instrument captured all the constructs of persistent pain. While the compendium focuses clinicians' choices on high quality, clinically useful instruments, clinicians should use multiple instruments to ensure comprehensive assessment of adults with persistent pain.

The compendium is available from New Zealand Accident Compensation Corporation. Health practitioners who have not, to date, used standard assessment instruments for persistent pain patients are encouraged to choose instruments from those provided in the compendium.

\section{Disclosures}

None of the authors have conflicts of interest to disclose.

\section{References}

1. Sackett DL, Straus SE, Richardson WS, Rosenberg W, Haynes RB. Evidence-based Medicine: How to practice and teach. London: Churchill Livingston; 2000.

2. Bowling A. Research Methods in Health: Investigating health and health services. 2nd ed. Philadelphia: Open University Press, Buckingham; 2002.

3. Streiner D. Clinimetrics vs psychometrics: an unnecessary distinction. J Clin Epidemiol. 2003;56(12):1142-1145.

4. Wind H, Gouttebarge V, Kuijer PP Frings-Dresen, MH. Assessment of functional capacity in the musculoskeletal system in the context of work, daily living and sport: a systematic review. J Occup Rehabil. 2005;15(2):253-272.

5. Siddall PJ, Cousins MJ. Persistent pain as a disease entity: Implications for clinical management. Anesth Analg. 2004;99(2):510-520.

6. Cousins MJ. Persistent Pain: A Disease Entity. J Pain Symptom Manage. 2007;33(2):S4-S10.

7. Blyth FM, March LM, Brnabic AJ, Jorm LR, Williamson M, Cousins MJ. Chronic pain in Australia. A prevalence study. Pain. 2001;89:127-134.
8. Blyth FM, March LM, Cousins MJ. Chronic pain-related disability and use of analgesic and health services in a Sydney community. Med $J$ Aust. 2003;179:84-87.

9. Blyth FM, March LM, Nicholas M, Cousins MJ. Chronic pain, work performance and litigation. Pain. 2003;103:41-47.

10. Blyth FM, March LM, Brnabic AJM, Cousins MJ. Chronic pain and frequent use of health care. Pain. 2004;111:51-58.

11. Indahl A, Haldorsen EMH, Holm S, Reikeras O, Olav MD. Five-year follow-up study of a controlled clinical trial using light mobilization and an informative approach to low back pain. Spine. 1998;23(23):2625-2630.

12. Hagen EM, Eriksen HR, Ursin H. Does early intervention with a light mobilization program reduce long-term sick leave for low back pain? Spine. 2000;25(15):1973-1976.

13. Gatchell RJ, Polatin PB, Noe C, Gardea M, Pulliam C, Thompson J. Treatment- and cost-effectiveness of early intervention for acute low-back pain patients: a one-year prospective study, J Occup Rehabil. 2003;13(1):1-9.

14. Wand BM, Bird C, McAuley JH, Dore CJ, MacDowell M, De Souza LH. Early intervention for the management of acute low back pain: a single-blind randomized controlled trial of biopsychosocial education, manual therapy, and exercise. Spine. 2004;29(21):2350-2356.

15. AHCPR. Acute Pain Management: Operative or Medical Procedures and Trauma, Clinical Practice Guideline No. 1, Publication No 92-0032, 1992. p. 116-117.

16. Texas Cancer Council. Guidelines for treatment of cancer pain: The revised pocket edition of the final report of the Texas cancer council's workgroup on pain control in cancer patients. [publication on the Internet]. 1997; [cited October 11, 2006] Available from http://www. texascancercouncil.org.

17. Von Korff M, Ormel J, Keefe FJ, Dworkin SF. Grading the severity of chronic pain. Pain. 1992;50(2):133-149.

18. Elliott AM, Smith BH, Smith WC, Chambers WA. Changes in chronic pain severity over time: the chronic pain grade as a valid measure. Pain. 2000;88(3):303-308.

19. Elliott AM, Smith BH, Hannaford PC, Smith WC, Chambers WA. Assessing change in chronic pain severity: the chronic pain grade compared with retrospective perceptions. Br J Gen Pract. 2002;52(477):269-274.

20. Von Korff M, Jensen MP, Karoly P. Assessing global pain severity by self-report in clinical and health services research. Spine. 2000;25(24):3140-3151.

21. Smith CA, Wallston KA, Dwyer KA, Dowdy SW. Beyond good and bad coping: a multidimensional examination of coping with pain in persons with rheumatoid arthritis. Ann Behav Med. 1999;19(1):11-21.

22. Melzack R. The McGill pain questionnaire: major properties and scoring methods. Pain. 1975;1(3):277-299.

23. Melzack R. The short-form McGill pain questionnaire. Pain. 1987;30(2):191-197.

24. Bouhassira D. The DN4 questionnaire: a new tool for the diagnosis of neuropathic pain. Douleurs. 2005;6(5):297-300.

25. Bouhassira D, Attal N, Alchaar H. Comparison of pain syndromes associated with nervous or somatic lesions and development of a new neuropathic pain diagnostic questionnaire (DN4). Pain. 2005;114(1-2):29-36.

26. Benzon HT. The neuropathic pain scales. Reg Anesth Pain Med. 2005;30(5):417-421.

27. Bennett M. The LANSS pain scale: the Leeds assessment of neuropathic symptoms and signs. Pain. 2001;92(1-2):147-157.

28. Backonja M. Need for differential assessment tools of neuropathic pain and the deficits of LANSS pain scale. Pain. 2002;98(1-2):229-230.

29. Bennett MI, Smith BH, Torrance N, Potter J. The S-LANSS score for identifying pain of predominantly neuropathic origin: validation for use in clinical and postal research. J Pain. 2005;6(3):149-158.

30. Benzon HT. The neuropathic pain scales. Reg Anesth Pain Med. 2005;30(5):417-421. 
31. Kaki AM, El-Yaski AZ, Youseif E. Identifying neuropathic pain among patients with chronic low-back pain: use of the Leeds assessment of neuropathic symptoms and signs pain scale. Reg Anesth Pain Med. 2005;30(5):422-428.

32. Orhan EK, Yucel A, Senocak M, Ertas M. The validation study results of LANSS pain scale. Agri-Istanbul. 2002;14(3):49-54.

33. Beck AT, Steer RA, Garbin MG. Psychometric properties of the beck depression inventory: twenty-five years of evaluation. Clin Psychol Rev. 1988;8(1):77-100.

34. Kessler RC, Andrews G, Colpe LJ, Hiripi E, Mroczek DK, Normand SLT, Walters EE, Zaslavsky AM. Short screening scales to monitor population prevalences and trends in non-specific psychological distress. Psychological Medicine. 2002;32(6):959-976.

35. Andrews G, Slade T. Interpreting scores on the kessler psychological distress scale (K10). Aust N Z J Public Health. 2001; 25(6):494-497.

36. Radloff LS. The CED-D scale: a self depression scale for research in the general population. Appl Psychol Meas. 1977;1:385-401.

37. Turk DC, Okifuji A. Detecting depression in chronic pain patients: adequacy of self-reports. Behav Res Ther. 1994;32(1):9-16.

38. Geisser ME, Roth RS, Robinson ME. Assessing depression among persons with chronic pain using the Center for Epidemiological Studies-Depression Scale and the Beck Depression Inventory: a comparative analysis. Clin J Pain. 1997;13(2):163-170.

39. Snaith RP. The Hospital Anxiety And Depression Scale. Health Qual Life Outcome. 2003;1:29.

40. Bjelland I, Dahl AA, Haug TT, Neckelmann D. The validity of the Hospital Anxiety and Depression Scale. An updated literature review. J Psychosom Res. 2002;52(2):69-77.

41. Main CJ. The modified somatic perception questionnaire (MSPQ). J Psychosom Res. 1983;27(6):503-514.

42. Deyo RA, Walsh NE, Schoenfeld LS, Ramamurthy S. Studies of the modified somatic perceptions questionnaire (MSPQ) in patients with back pain. Psychometric and predictive properties. Spine 1989;14(5):507-510

43. Waddell G, Newton M, Henderson I, Somerville D, Main CJ. A fear-avoidance beliefs questionnaire (FABQ) and the role of fear-avoidance beliefs in chronic low back pain and disability. Pain. 1993;52(2):157-168.

44. Crombez G, Vlaeyen JW, Heuts PH, Lysens R. Pain-related fear is more disabling than fear itself: evidence on the role of pain-related fear in chronic back pain disability. Pain. 1999;80(1-2):329-339.

45. Woby SR, Roach NK, Urmston M, Watson PJ. Psychometric properties of the TSK-11: a shortened version of the Tampa scale for kinesiophobia. Pain. 2005;117(1-2):137-144.

46. Osman A, Barrios FX, Gutierrez PM, Kopper BA, Butler A, Bagge CL. The Pain Distress Inventory: development and initial psychometric properties. J Clin Psychol. 2003;59(7):767-785.

47. Philips HC, Jahanshahi M. The components of pain behaviour report Behav Res Ther. 1986;24(2):117-125.

48. Anciano $\mathrm{D}$. The pain behaviour checklist: factor analysis and validation. Br J Clin Psychol. 1986;25(4):301-302.

49. McCracken LM, Yang SY. The role of values in a contextual cognitivebehavioural approach to chronic pain. Pain. 2006;123(1-2):137-145.

50. Nielson W, Jensen MP, Kerns RD. Initial development and validation of a multidimensional pain readiness to change questionnaire. $J$ Pain. 2003;4(3):148-158.

51. Nicholas MK. The pain self-efficacy questionnaire: taking pain into account. Eur J Pain. 2007;11(2):153-163.

52. Jensen MP, Turner JA, Romano JM, Strom SE. The chronic pain coping inventory: development and preliminary validation. Pain 1995;60(2):203-216.

53. Romano JM, Jensen MP, Turner JA. The chronic pain coping inventory-42: reliability and validity. Pain. 2003;104(1-2):65-73.

54. Jensen MP, Keefe FJ, LefebvreJC, Romano JM, Turner JA. Oneand two-item measures of pain beliefs and coping strategies. Pain. 2003;104(3):453-469.
55. Rosenstiel AK, Keefe FJ. The use of coping strategies in chronic low back pain patients: relationship to patient characteristics and current adjustment. Pain. 1983b;17(1):33-44.

56. Harland NJ, Georgieff K. Development of the coping strategies questionnaire 24, a clinically utilitarian version of the coping strategies questionnaire. Rehabil Psychol. 2003;48(4):296-300.

57. Kraaimaat FW, Bakker A, Evers AW. Pain coping strategies in chronic pain patients: the development of the pain coping inventory (PCI). Gedragstherapie. 1997;30(3):185-201.

58. McCracken LM. Behavioural constituents of chronic pain acceptance: results from factor analysis of the chronic pain acceptance questionnaire. J Back Musculoskeletal Rehabil. 1999;13(2-3):93-100.

59. McCracken LM, Vowles KE, Eccleston C. Acceptance of chronic pain: component analysis and a revised assessment method. Pain 2004;107(1-2):159-166.

60. Cook AJ, Degood DE. The cognitive risk profile for pain: development of a self-report inventory for identifying beliefs and attitudes that interfere with pain management. Clin J Pain. 2006;22(4):332-345.

61. Dalton JA, Feuerstein M, Carlson J, Roghman K. Biobehavioral pain profile: development and psychometric properties. Pain. 1994;57(1):95-107.

62. Lerner D, Amick BC, Rogers WH, Malspeis S, Bungay K, Cynn D The work limitations questionnaire. Med Care. 2001;39(1):72-85.

63. Lerner D, Reed JI, Massarotti E, Wester LM, Burke TA. The work limitations questionnaire's validity and reliability among patients with osteoarthritis. J Clin Epidemiol. 2002;55(2):197-208.

64. Kopec JA, Esdaile JM. Occupational role performance in persons with back pain', Disability and Rehabilitation. 1998;20(10):373-379.

65. Williams RM, Myers AM. Functional abilities confidence scale: a clinical measure for injured workers with acute low back pain. Phys Ther. 1998b;78(6):624-634.

66. Williams RM, Myers AM. A new approach to measuring recovery in injured workers with acute low back pain: resumption of activities of daily living scale. Phys Ther. 1998a;78(6):613-623.

67. Pollard CA. Preliminary validity study of the pain disability index. Percept Mot Skills. 1984;59(3):974.

68. Kliempt P, Ruta D, McMurdo M. Measuring the outcomes of care in older people: a non-critical review of patient-based measures. III. Pain, physical disability and handicap, and social health instruments. Rev Clin Gerontol. 2000;10:235-244.

69. Åsenlöf P, Denison E, Lindberg P. Behavioural goal assessment in patients with persistent musculoskeletal pain. Physiother Theory Pract. 2004;20(4):243-254.

70. Stratford P, Gill C, Westaway M, Binkley J. Assessing disability and change on individual patients: a report of a patient specific measure. Physiother Can. 1995;47(4):258-263.

71. Chatman AB, Hyams SP, Neel JM, Binkley JM, Stratford PW, Schomberg A, Stabler M. The patient-specific functional scale: measurement properties in patients with knee dysfunction. Phys Ther. 1997;77(8):820-829.

72. Westaway MD, Stratford PW, Binkley JM. The patient-specific functional scale: validation of its use in persons with neck dysfunction. J Orthop Sports Phys Ther. 1998;27(5):331-338.

73. Millard RW. The functional assessment screening questionnaire: application for evaluating pain-related disability. Arch Phys Med Rehabil. 1998;70(4):303-307.

74. Cleeland CS, Ryan KM. Pain assessment: global use of the brief pain inventory. Ann Acad Med. 1994;23(2):129-138.

75. Jensen MP, Hoffman AJ, Cardenas DD. Chronic pain in individuals with spinal cord injury: a survey and longitudinal study. Spinal Cord. 2005;43(12):704-712.

76. Newton-John TR. The family impact of pain scale: preliminary validation. J Clin Psychol Med Settings. 2005;12(4):349-358.

77. Schwartz L, Kraft GH. The role of spouse responses to disability and family environment in multiple sclerosis. Am J Phys Med Rehabil. 1999;78(6):525-532. 
78. Law M, Baptiste S, McColl MA, Opzoomer A, Polatajko H, Pollock N. The Canadian occupational performance measure: an outcome measure for occupational therapy. Can J Occup Ther. 1990;57(2):82-87.

79. Carpenter L, Baker GA, Tyldesley B. The use of the canadian occupational performance measure as an outcome of a pain management program. Can J Occup Ther. 2001;68(1):16-22.

80. Jolles BM, Buchbinder R, Beaton DE. A study compared nine patientspecific indices for musculoskeletal disorders. J Clin Epidemiol. 2005;58(8):791-801.

81. Persson E, Rivano-Fischer M, Eklund M. Evaluation of changes in occupational performance among patients in a pain management program. J Rehabil Med. 2004;36(2):85-91.

82. Walsh DA, Kelly SJ, Johnson SP, Rajkumar S, Bennetts K. Performance problems of patients with chronic low-back pain and the measurement of patient-centered outcome. Spine. 2004;29(1):87-93.

83. Corson JA, Schneider MJ. The Dartmouth pain questionnaire: an adjunct to the McGill pain questionnaire. Pain. 1984;19(1):59-69.

84. Durand MJ, Loisel P, Hong QN, Charpentier N. Helping clinicians in work disability prevention: the work disability diagnosis interview. J Occup Rehabil. 2002;12(3):191-204.

85. Marhold C, Linton SJ, Melin L. Identification of obstacles for chronic pain patients to return to work: evaluation of a questionnaire. $J$ Occup Rehabil. 2002;12(2):65-75.

86. Linton SJ, Hallden K. Can we screen for problematic back pain? A screening questionnaire for predicting outcome in acute and subacute back pain. Clin J Pain. 1998;14(3):209-215.

87. Boersma K, Linton SJ. Screening to identify patients at risk: profiles of psychological risk factors for early intervention. Clin J Pain. 2005;21(1):38-43.

88. Dunstan DA, Covic T, Tyson GA, Lennie IG. Does the Orebro musculoskeletal pain questionnaire predict outcomes following a work-related compensable injury? Int J Rehabil Res. 2005;28(4):369-370.

89. Grotle M, Vollestad NK, Brox JI. Screening for yellow flags in firsttime acute low back pain: reliability and validity of a Norwegian version of the acute low back pain screening questionnaire. Clin J Pain. 2006b;22(5):458-467.

90. Hurley DA, Dusoir TE, McDonough SM, Moore AP, Baxter GD. How effective is the acute low Clin J Pain. 2001;17(3):256-263.

91. Kerns RD, Turk DC, Rudy TE. The West Haven-Yale multidimensional pain inventory (WHYMPI). Pain. 1985;23(4):345-356.

92. Kerns RD, Rosenberg R. Pain-relevant responses from significant others: development of a significant-other version of the WHYMPI scales. Pain. 1995;61(2):245-249.

93. Euroqol Group. EuroQol - a new facility for the measurement of healthrelated quality of life. Health Policy (New York). 1990;16(3):199-208.

94. WHOQOL Group. The world health organization quality of life assessment (WHOQOL): position paper from the world health organization. Soc Sci Med. 1995;41(10):1403-1409.

95. Kaplan RM, Bush JW, Berry CC. Health status: types of validity and the index of well-being,' Health Serv Res. 1976;11(4):78-507.

96. Bergner M, Bobbitt RA, Kressel S, Pollard WE, Gilson BS, Morris JR. The sickness impact profile: conceptual formulation and methodology for the development of a health status measure. Int J Health Serv. 1976;6(3):393-415.

97. Claiborne N, Krause TM, Heilman AE, Leung P. Measuring quality of life in back patients: comparison of health status questionnaire 2.0 and quality of life inventory. Soc Work Health Care. 1999;28(3):7-94.

98. Ware JR, Sherbourne C. The MOS-36 item short form health survey 1: conceptual framework and item selection. Med Care. 1992;30(6):473-483.

99. Scott KM, Tobias MI, Sarfati D, Haslett SJ. SF-36 health survey reliability, validity and norms for New Zealand. Aust N ZJ Public Health. 1999;23(4):401-406.

100. Ebrahim S, Barer D, Nouri F. Use of the Nottingham health profile with patients after a stroke. J Epidemiol Community Health. 1986;40(2):166-169.
101. Wann-Hansson C, Hallberg IR, Risberg B, Klevsgård R. A comparison of the Nottingham health profile and short form 36 health survey in patients with chronic lower limb ischaemia in a longitudinal perspective. Health Qual Life Outcomes. 2004;2:9.

102. Collins SL, Moore RA, McQuay HJ. The visual analogue pain intensity scale: what is moderate pain in millimetres? Pain. 1997;72(1-2):95-97.

103. Galer BS, Jensen MP. Development and preliminary validation of a pain measure specific to neuropathic pain: the neuropathic pain scale. Neurology. 1997;48(2):332-338.

104. Bouhassira D, Attal N, Fermanian J, et al. Development and validation of the neuropathic pain symptom inventory. Pain. 2004;108(3): 248-257.

105. Portenoy R. Development and testing of a neuropathic pain screening questionnaire: ID pain. Curr Med Res Opin. 2006;22(8):1555-1565.

106. Krause SJ, Backonja MM. Development of a neuropathic pain questionnaire. Clin J Pain. 2003;19(5):306-314.

107. Pincus T, Williams AC, Vogel S, Field A. The development and testing of the depression, anxiety, and positive outlook scale (DAPOS). Pain. 2004;109(1-2):181-188.

108. Beck AT, Ward CH, Mendelson M, Mock J, Erbaugh J. An inventory for measuring depression. Arch Gen Psychiatry. 1961;4:53-63.

109. Zigmond AS, Snaith RP. The hospital anxiety and depression scale. Acta Psychiatr Scand. 1983;67(6):361-370.

110. Zung WW. A self-rating depression scale. Arch Gen Psychiatry. 1965;12:63-70.

111. Butler RW, Damarin FL, Beaulieu C, Schwebel AI, Thorn BE. Assessing cognitive coping strategies for acute post-surgical pain. Psychol Assess. 1989;1(1):41-45.

112. McCracken LM, Zayfert C, Gross RT. The pain anxiety symptoms scale: development and validation of a scale to measure fear of pain. Pain. 1992;50(1):67-73.

113. Vlaeyen JW, Geurts SM, Kole-Snijders AM, Schuerman JA, Groenman NH, van Eek H. What do chronic pain patients think of their pain? Towards a pain cognition questionnaire. Br J Clin Psychol. 1990;29(Pt 4):383-394.

114. Boston K, Pearce SA, Richardson PH. The pain cognitions questionnaire. J Psychosom Res. 1990;34(1):103-109.

115. Gil K, Williams DA, Keefe FJ, Beckham JC. The relationship of negative thoughts to pain and psychological distress. Behav Ther. 1990;21(3):349-362.

116. Sullivan MJ, Bishop SR, Pivik J. The pain catastrophizing scale: development and validation. Psychol Assess. 1995;7(4):524-532.

117. Crowley D, Kendall NA. Development and initial validation of a questionnaire for measuring fear-avoidance associated with pain: the fear-avoidance of pain scale. J Muscoskel Pain. 1999;7(3):3-19.

118. Rainwater AJ. The role of experienced pain in the assessment of fear of pain: a predictive validity study of the fear of pain questionnaireIII. PhD Thesis. USA: Oklahoma State University; 1999.

119. Miller R, Kori S, Todd D. The Tampa Scale. Ministry of Health NZ. 1999. [cited November 11, 2006]. Available from: http://www.moh. govt.nz/moh.nsf/f872666357c511eb4c25666d000c8888/fac6e672dc ee5aa8cc256edf00742bb7?OpenDocument.

120. McCracken LM. Attention to pain in persons with chronic pain: a behavioural approach,' Behav Ther. 1997;28(2):271-284.

121. Hardt J, Gerbershagen HU. Cross-validation of the SCL-27: a short psychometric screening instrument for chronic pain patients. Eur $J$ Pain. 2001;5(2):187-197.

122. Main CJ, Wood PL, Hollis S, Spanswick CC, Waddell G. The distress and risk assessment method. A simple patient classification to identify distress and evaluate the risk of poor outcome. Spine. 1992;17(1):42-52.

123. Riley JF, Ahern DK, Follick MJ. Chronic pain and functional impairment: assessing beliefs about their relationship. Arch Phys Med Rehabil. 1988;69(8):579-582.

124. Rosenstiel AK, Keefe FJ. Coping strategies questionnaire (CSQ). Athens, OH: Ohio University; 1983a. 
125. Yong HH, Bell R, Workman B, Gibson SJ. Psychometric properties of the pain attitudes questionnaire (revised) in adult patients with chronic pain. Pain. 2003;104(3):673-681.

126. Crow CS, Olivet LW, Burry-Stock J, VanderMeer JL. Assessment of pain coping styles: development of an inventory. $J$ Adv Nurs. 1996;24(5):890-898.

127. Smith BH, Penny KI, Purves AM. The chronic pain grade questionnaire: validation and reliability in postal research. Pain. 1997;71(2):141-147.

128. Geiser DS. A comparison of acceptance-focused and control-focused psychological treatments in a chronic pain treatment center. Unpublished doctoral dissertation. Reno: University of Nevada; 1992.

129. McCracken LM, Eccleston C, Bell L. Clinical assessment of behavioural coping responses: preliminary results from a brief inventory. Eur J Pain. 2005;9(1):69-78.

130. Jensen MP, Karoly P, Huger R. The development and preliminary validation of an instrument to assess patients' attitudes toward pain. J Psychosom Res. 1987;31(3):393-400.

131. Edwards LC, Pearce SA, Turner-Stokes L, Jones A. The pain beliefs questionnaire: an investigation of beliefs in the causes and consequences of pain. Pain. 1992;51(3):267-272.

132. Williams DA, Thorn BE. An empirical assessment of pain beliefs. Pain. 1989;36(3):351-8.

133. ter Kuile MM, Linssen ACG, Spinhoven P. The development of the multidimensional locus of pain control questionnaire (MLPC): factor structure, reliability, and validity. J Psychopathol Behav Assess. 1993;15(4):387-404

134. De Vlieger P, Bussche EV, Eccleston C, Crombez G. Finding a solution to the problem of pain: conceptual formulation and the development of the pain solutions questionnaire (PaSol). Pain. 2006;123(3):285-293.

135. Tollison DC, Langley JC. Pain patient profile manual. Minneapolis: National Computer Services; 1995

136. Anderson K, Dowds B, Pelletz R, Edwards W, Peeters-Asdourian C. Development and initial validation of a scale to measure self-efficacy beliefs in patients with chronic pain. Pain. 1995;63(1):77-84.

137. Zarkowska AW. The relationship between subjective and behavioural aspects of pain in people suffering from lower back pain. M.Phil thesis. London: University of London; 1981.

138. Kerns RD, Rosenberg R, Jamison RN, Caudill MA, Haythornthwaite J. Readiness to adopt a self-management approach to chronic pain: the pain stages of change questionnaire (PSOCQ). Pain. 1997;72(1-2):227-234.

139. Nicholas. M. An evaluation of cognitive, behavioural and relaxation treatments for chronic low back pain. $\mathrm{PhD}$ thesis. Sydney: University of New South Wales; 1988.

140. Amick B, Lerner D, Rogers W, Rooney T, Katz J. A review of healthrelated work outcome measures and their uses, and recommended measures. Spine. 2000;25(24):3152-3160.

141. Halpern M, Hiebert R, Nordin M, Goldsheyder D, Crane M. The test-retest reliability of a new occupational risk factor questionnaire for outcome studies of low back pain. Appl Ergon. 2001;32(1):39-46.

142. Vallerand AH. Development and testing of the inventory of functional status - chronic pain. J Pain Symptom Manage. 1998;15(2):125-133.

143. Vindigni D, Parkinson L, Rivett D, et al. Developing a musculoskeletal screening survey for Indigenous Australians living in rural communities. Rural Remote Health. 2006;6(1):321.

144. Cleeland CS. Brief pain inventory (BPI). Fabry Registry. 1982; [cited 2 August 2007]. Available from: http://www.mdanderson. org/pdf/bpisf.pdf
145. Ferguson RJ, Seville J, Cole B, et al. Psychometric update of the functional interference estimate: a brief measure of pain functional interference. J Pain Symptom Manage. 2004;28(4):389-395.

146. Pollard CA. The relationship of family environment to chronic pain disability. PhD thesis. San Diego: California School of Professional Psychology; 1981.

147. Anagnostis C, Gatchel R, Mayer T. The pain disability questionnaire: a new psychometrically sound measure for chronic musculoskeletal disorders. Spine. 2004;29(20):2290-2302.

148. Schwartz L, Jensen MP, Romano JM. The development and psychometric evaluation of an instrument to assess spouse responses to pain and well behaviour in patients with chronic pain: the spouse response inventory. J Pain. 2005;6(4):243-252.

149. Robinson ME, Brown JL, George SZ, et al. Multidimensional success criteria and expectations for treatment of chronic pain: the patient perspective. Pain Med. 2005;6(5):336-345.

150. Granger CV, Ottenbacher KJ, Baker JG, Sehgal A. 'Reliability of a brief outpatient functional outcome assessment measure. Am J Phys Med Rehabil. 1995;74(6):469-475.

151. Linton SJ, Hallden K. Risk factors and the natural course of acute and recurrent musculoskeletal pain: developing a screening instrument. Proceedings of the 8th World Congress on Pain; Seattle; IASP Press; 1996.

152. Thomas RJ, McEwen J, Asbury AJ. The Glasgow pain questionnaire: a new generic measure of pain; development and testing. Int J Epidemiol. 1996;25(5):1060-1067.

153. Mossey JM, Kerr ND, Welz-Bosna M, Gallagher RM. Preliminary evaluation of the health background questionnaire for pain and clinical encounter form for pain. Pain Med. 2005;6(6):443-451.

154. Hunter New England NSW Health. Hunter Integrated Pain Service (HIPS) Patient Screening Questionnaire (HIPSPSQ).[cited August 2, 2007]. Available from: www.hunter.health.nsw.gov. $\mathrm{au} /$ docs/HIPS-PatientScreeningQuestionnaire-V4.pdf $>$ [website updated May 2008: [cited 16 December 2008] available from: http:/www.hnehealth.nsw.gov.au/_data/assets/pdf_file/0020/45812/ Patient_Screening_QuestionnaireMay_08.pdf.

155. Clark ME, Gironda RJ, Young RW. Development and validation of the pain outcomes questionnaire-VA. J Rehabil Res Dev. 2003;40(5):381-395.

156. Waddell G, Burton AK, Main CJ. Screening to identify people at risk of long-term incapacity for work: a conceptual and scientific review. London: Royal Society of Medicine Press; 2003.

157. Ruehlman LS, Karoly P, Newton C, Aiken LS. The development and preliminary validation of brief measure of chronic pain impact for use in the general population. Pain. 2005;113(1-2):82-90.

158. Ruehlman LS, Karoly P, Newton C, Aiken LS. The development and preliminary validation of the profile of chronic pain: extended assessment battery. Pain. 2005;118(3):380-389.

159. Health Outcomes Institute. Health Status Questionnaire 2.0: user guide. Medical Center: Boston, MA; 1993.

160. Hunt SM, McKenna SP, Williams. Reliability of a population survey tool for measuring perceived health problems: a study of patients with osteoarthrosis. J Epidemiol Community Health. 1981;35(4):297-300.

161. McCracken LM, Gross RT, Aikens J, Carnrike CL. The assessment of anxiety and fear in persons with chronic pain: a comparison of instruments. Behav Res Ther. 1996;34(11-12):927-933. 


\section{Appendix I \\ Search strategy}

The search strategy incorporated all possible variations of nomenclature relating to persistent pain assessment. The search sought to identify:

- all questionnaires, surveys, instruments and rating scales developed to assess persistent pain in adults who had noncancer pain, and

- developmental literature including psychometric testing of these instruments.

Concurrently, background literature was sought on:

- biomedical, functional, behavioral, and psychosocial aspects relevant to persistent pain assessment

- risk factors for developing persistent (noncancer) pain

- special populations (indigenous, rural, and remote) and instruments specifically developed to address their needs, and

- different methods of administration of assessment instruments (in person, via telephone or mail).

\section{Search terms}

MeSH subject headings: pain measurement, persistent pain, questionnaires, indigenous population
Non-MeSH search terms: tool*, scale*, inventor*, questionnaire*, protocol*, survey*, profile*, model*, drawing*, checklist*, index, pain, pain assessment, persist*, functional, biomedical, psychosocial, psycholog*, behaviour*, behavior*, risk, assess*, screen*, rural, indigenous, maori, postal, telephone, psychometric, valid, reliab*, respons*. The search terms and strategies were amended as required for other databases.

\section{Library databases and internet sites}

All available databases were accessed through university library sources. The 'parent' data bases sourced mainstream academic databases which list the peer reviewed literature, including OVID (AMED, CINAHL, MEDLINE, EMBASE) and INFORMIT (AUSThealth, INFORMIT Plus Text [Meditext], INFORMIT e-library). These principal databases were interrogated first and publications sourced from these databases contributed more than $95 \%$ of the literature reviewed.

To ensure rigor in searching of literature, other secondary databases to validate the initial findings were then searched, including, but not limited to, PsychINFO, PsycARTICLES, Science Direct, Web of Science, PubMed, etc. Interrogation of these databases revealed mostly redundant duplicate publications, already identified from the larger databases. 


\section{Appendix 2 \\ Persistent pain severity}

Unidimensional measure of pain severity

Multidimensional pain assessment instruments

Discriminating neuropathic and nonneuropathic pain
Visual Analogue Scale (VAS) [10 cm line] (reported, ${ }^{22}$ discriminant values ${ }^{102}$

Verbal Rating Scale (VRS) [word descriptors] ${ }^{15}$

Numeric Rating Scale (NRS) [0-10 categories $]^{15}$

Chronic Pain Grade (CPG) ${ }^{17}$

McGill Pain Questionnaire Long form (MPQ_LF) ${ }^{22}$

McGill Pain Questionnaire Short form (MPQ_SF) ${ }^{23}$

Neuropathic Pain Scale (NPS) ${ }^{103}$

Neuropathic Pain Symptom Inventory (NPSI) ${ }^{104}$

Douleur Neuropathique 4 (DN4) $)^{25}$

IDPain $^{105}$

Leeds Assessment of Neuropathic Symptoms and Signs

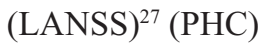

Neuropathic Pain Questionnaire Long Form (NPQ_LF) ${ }^{106}$

Neuropathic Pain Questionnaire Short Form (NPQ_SF) ${ }^{106}$

\section{Psychological assessment of chronic pain}

Psychological states not

directly related to persistent pain

Measurement of anxiety, depression, and mood

Physiological manifestations of anxiety and depression relative to persistent pain

Pain cognition

Catastrophizing, negative thoughts, fear
Depression, Anxiety, and Positive Outlook (DAPOS) ${ }^{107}$

Beck Depression Inventory (BDI) ${ }^{108}$ (peer reviewer)

Center for Epidemiologic Studies-Depression Scale $(\mathrm{CES}-\mathrm{D})^{36}$

Hospital Anxiety and Depression Scale (HADS) ${ }^{109}$

(ACC Pain Focus Group)

Kessler Psychological Distress Scale (K10) $)^{34}$

Zung Self-Rating Depression Scale (ZSRD) ${ }^{110}$

Modified Somatic Perception Questionnaire (MSPQ) ${ }^{41}$

Cognitive Coping Strategies Inventory-Revised

$(\text { CCSI-R })^{111}$

Pain Anxiety Symptoms Scale (PASS-SF(20), PASS-40, PASS-72) ${ }^{112}$

Pain Cognition List (PCL) $)^{113}$

Pain Cognitions Questionnaire (PCQ) ${ }^{114}$

Negative thoughts about pain

Inventory of Negative Thoughts in Response to Pain $(\text { INTRP) })^{115}$

Catastrophizing

Pain Catastrophizing Scale (PCS) (includes a scale for the significant other/partner PCS_S $)^{116}$ 
Risk factor identification

Pain function, coping $\&$ management

\section{Persistent pain fear}

1. Fear-Avoidance Beliefs Questionnaire (FABQ $)^{43}$

2. Fear Avoidance of Pain Scale (FAPS) ${ }^{117}$

3. Fear of Pain Comparisons (FPC_11) ${ }^{118}$

4. Tampa Scale for Kinesiophobia (TSK) ${ }^{119}$

5. Tampa Scale for Kinesiophobia Short version $(\mathrm{TSK}-11)^{45}$

Pain distress

Pain Distress Inventory (PDI) ${ }^{46}$

Vigilance, preoccupation, and awareness of pain

Pain Vigilance and Awareness Questionnaire (PVAQ) ${ }^{120}$

Psychopathology in persistent pain

Symptoms of Chronic Pain List (SCL_27) ${ }^{121}$

Distress and Risk Assessment Method (DRAM) ${ }^{122}$

Ability to function with persistent pain

Pain and Impairment Relationship Scale (PAIRS) ${ }^{123}$

Persistent pain coping

1. Chronic Pain Coping Inventory suite (CPCI_65 (CPCI_significant other, CPCI_42, and CPCI_abbreviated) $)^{52}$

2. Coping Strategies Questionnaire (CSQ_50) ${ }^{124}$ which also includes a revised (CSQ_R(27)), a shorter version (CSQ24)56 (and an abbreviated version (CSQ_abbreviated) $)^{54}$

3. Stoicism (Pain Attitudes Questionnaire-Revised (PAQR)) 125 Pain-Coping Inventory (PCI) ${ }^{57}$

4. Pain Coping Style Inventory (PCSI) ${ }^{126}$

5. Vanderbilt Multidimensional Pain Management Inventory (VMDPMI) ${ }^{127}$

Acceptance of persistent pain

Chronic Pain Acceptance Questionnaire (CPAQ) ${ }^{128}$

Persistent pain management beliefs

Cognitive Risk Profile for Pain (CRPP) ${ }^{60}$

Reactions to persistent pain

1. Brief Pain Coping Inventory (BPCI) ${ }^{129}$

2. Biobehavioral Pain Profile (BPP) ${ }^{61}$

Pain attitudes

Survey of Pain Attitudes (SOPA_57), ${ }^{130}$ which includes a 35 item version (SOPA_35) and a short version

(SOPA_S)

Pain beliefs and consequences

Pain Beliefs Questionnaire (PBQ) $)^{131}$

Pain beliefs and knowledge 
Behavioral change readiness
Pain Beliefs and Perceptions Inventory (PBPI) ${ }^{132}$

Psychological pain functioning

1. Multidimensional Locus of Pain Control Questionnaire (MLPC) $^{133}$

2. Pain Solutions Questionnaire (PaSolQ) ${ }^{134}$

3. Pain Patient Profile (PPP) ${ }^{135}$

Chronic pain self-efficacy scale (CPS-ES) ${ }^{136}$

Chronic Pain Values Inventory (CPVI) ${ }^{49}$

Multidimensional Pain Readiness to Change

Questionnaire (MPRCQ) ${ }^{50}$

Pain Behavior Checklist (PBC) ${ }^{137}$

Pain Stages of Change Questionnaire (PSCQ) ${ }^{138}$

Pain Self Efficacy Questionnaire (PSEQ) ${ }^{139}$

Eighteen instrument suites (25 instruments) were identified, these being BDI, BPP, CES-D, CPAQ, CPCI suite of four instruments, CPVI, CRPP, CSQ suite of four instruments, FABQ, HADS, K10, MPRCQ, MSPQ, PBC, PCI, PSEQ, TSK suite of 2 instruments, ZSRD.

\section{Functional capacity}

Occupation focus

General function (women only)

General function

General function (Indigenous health)

Interference (disability) in functional activities

Impact on others

Patient-specific instruments

Performance
Work Limitations Questionnaire suite (WLQ) ${ }^{62}$

Work Limitations-26 (WL-26) ${ }^{140}$

Occupational Role Questionnaire (OccRQ) ${ }^{64}$

Risk Factor Questionnaire (RFQ) ${ }^{141}$

Inventory of Functional Status - chronic pain (IFS-CP) ${ }^{142}$

Functional Abilities Confidence Scale (FACS) ${ }^{65}$

Resumption of Activities of Daily Living Scale (RADL) ${ }^{66}$

Kempsey Survey of Muscle, Joint and Bone Conditions $(\text { KSMBJC) })^{143}$

Brief Pain Inventory-Interference (BPI_I) ${ }^{144}$ (7-item derivative of BPI_LF, ${ }^{74}$ developed into a 12 -item instrument ${ }^{75}$ for disabled persons)

Functional Assessment Screening Questionnaire $(\text { FASQ) })^{73}$

Functional Interference Estimate (FIE) ${ }^{145}$

Pain Disability Index (PDI) ${ }^{146}$

Pain Disability Questionnaire (PDQ) ${ }^{147}$

Family Impact of Pain Scale (FIPS) ${ }^{76}$

Spouse Response Inventory (SRI) ${ }^{148}$

Patient Goal Priority Questionnaire (PGPQ) ${ }^{69}$

Patient-Specific Functional Scale (PSFS) ${ }^{70}$

Canadian Occupational Performance Measure (COPM) ${ }^{78}$ 


\section{Multidimensional assessment of persistent pain}

Occupational issues

Expectations

Yellow flags

Pain dimensions

Prediction of future disability (LBP only)

Pain profiling and outcome prediction instruments

Compilation or adaptation of existing instruments
Obstacles to Return-to-Work Questionnaire (ObsRWQ) ${ }^{85}$

Patient Centered Outcomes Questionnaire (PCOQ) ${ }^{149}$

Medical Rehabilitation Follow Along measure

(MRFA) - Musculoskeletal form ${ }^{150}$

Örebro Musculoskeletal Pain Screening Questionnaire (ÖMPSQ). This uses exactly the same wording as the Acute Low Back Screening Questionnaire (Yellow Flags) already in use by ACC in the Acute Low Back Pain guidelines. ${ }^{151}$ The ÖMPSQ includes a wide range of body parts likely to be affected by musculoskeletal pain.

Obstacles to Return-to-Work Questionnaire (ObsRWQ)

(listed above) ${ }^{85}$ contains items relating to depression

Brief Pain Inventory (BPI) ${ }^{144}$ (original (also known as the long form))

Brief Pain Inventory (BPI-SF) ${ }^{144}$ (short form)

Glasgow Pain Questionnaire (GPQ) ${ }^{152}$

Health Background Questionnaire for Pain (HBQP) $)^{153}$

Hunter Integrated Pain Service (HIPS) Patient Screening Questionnaire (HIPSPSQ) (no published reference) ${ }^{154}$

Obstacles to Return-to-Work Questionnaire (ObsRWQ) ${ }^{85}$

(listed above and reporting pain experiences).

Pain Outcomes Questionnaire suite of six instruments (POQ) Intake and Pain Outcomes Questionnaire-Short Form (POQ-42, POQ-SF, POQ-DC-28 [discharged from acute care], POQ-FU-34 [at follow-up], POQ-DC-5 [satisfaction scale extracted from POQ-DC-28]) ${ }^{155}$

West Haven-Yale Multidimensional Pain Inventory (WHYMPI) ${ }^{91}$ including the WHYMPI_S (Significant Other Instrument)

Vermont Disability Prediction Questionnaire (VDPQ) ${ }^{156}$

Profile of Chronic Pain: Screen (PCP:S) ${ }^{157}$

Profile of Chronic Pain: Extended Assessment Battery

(PCP:ES) $)^{158}$

Pain Outcomes Profile (POP) ${ }^{155}$

Dartmouth Pain Questionnaire (DPQ) (enhancing items from McGill Pain Questionnaire [MPQ] $)^{83}$

Work Disability Diagnosis Interview (WDDI) ${ }^{84}$ involves interview which consists partly of questions compiled by instrument authors and partly of a range of standardised questionnaires such as the Oswestry Disability Index, Fear-Avoidance Beliefs Questionnaire and Work APGAR. 


\section{General health/Quality of life assessment}

EuroQol (EQ-5D) $)^{93}$

Health Status Questionnaire 2.0 (HSQ) $)^{159}$

Nottingham Health Profile (NHP) ${ }^{160}$

Quality of Well-Being Scale - Self-Administered (QWBS) ${ }^{95}$

World Health Organization Quality of Life (WHOQOL) ${ }^{94}$ (including a short form WHOQOL-Bref)

Short Form-36 Health Survey (SF36) ${ }^{98}$

Sickness Impact Profile (SIP) ${ }^{96}$ 


\section{Appendix 3}

\section{Excluded instruments}

\section{Persistent pain severity}

Lack of published literature: At the time of the review, there was no published literature on psychometric properties of the instrument IDPain, and this instrument was excluded from further consideration.

Contact with author: Despite repeated attempts, no contact was able to be made with the author of the NPS (Galer) and thus this instrument was excluded after psychometric property evaluation.

Primary function: The NPSI is mainly reported in the literature as an outcome measure, not an assessment instrument, and it was thus excluded from further consideration.

\section{Psychological assessment of persistent pain}

Twenty-six instrument suites (31 instruments) were excluded during Step 2. The instruments, and primary reasons for exclusion, are listed below.

1. Brief Pain Coping Inventory (BPCI) no information on administration or scoring

2. Cognitive Coping Strategies Inventory-Revised (CCSI-R) no psychometric properties

3. Chronic Pain Self-Efficacy Scale (CPS-ES) limited evidence of strong psychometric properties

4. Depression, Anxiety and Positive Outlook (DAPOS) limited evidence of strong psychometric properties

5. Distress and Risk Assessment Method (DRAM) replicates questions in MSPQ and Zung instruments, minimum psychometric properties

6. Fear Avoidance of Pain Scale (FAPS) No information on psychometric properties

7. Fear of Pain Comparisons (FPC) uncertain clinical utility $^{161}$. Found it was less useful than the PASS and $F A B Q$ for understanding chronic pain

8. Inventory of Negative Thoughts in Response to Pain (INTRP) limited evidence of strong psychometric properties

9. Multidimensional Locus of Pain Control Questionnaire (MLPC) authors stated that further work is required on the instrument's psychometric properties, particularly aspects of validity. The PSCQ covers this area better.
10. Pain and Impairment Relationship Scale (PAIRS) limited evidence of strong psychometric properties

11. Pain Attitudes Questionnaire-Revised (PAQ-R) limited evidence of strong psychometric properties

12. Pain Solutions Questionnaire (PaSolQ) validity untested in English language

13. Pain Anxiety Symptoms Scale (PASS-20, PASS-40, PASS-72) limited evidence of strong psychometric properties, wordy instrument with multiple items in the long forms, uncertain psychometric properties in the short form

14. Pain Beliefs and Perceptions Inventory (PBPI) limited evidence of strong psychometric properties

15. Pain Beliefs Questionnaire (PBQ) unable to trace authors, minimum evidence of psychometric properties

16. Pain Cognition List (PCL) limited evidence of strong psychometric properties, scoring instructions only available in Dutch

17. Pain Cognitions Questionnaire (PCQ) unable to trace the authors

18. Pain Catastrophizing Scale (PCS) limited evidence of strong psychometric properties

19. Pain Coping Style Inventory (PCSI) uses AVAS for scoring all items, minimum psychometric properties, replicates other more readily scored instruments

20. Pain Distress Inventory (PDI) could not contact developers

21. Pain Patient Profile (PPP) limited information on psychometric testing

22. Pain Stages of Change Questionnaire (PSCQ) limited evidence of strong psychometric properties

23. Pain Vigilance and Awareness Questionnaire (PVAQ) limited evidence of strong psychometric properties

24. Symptoms of Chronic Pain List (SCL_27) limited evidence of strong psychometric properties

25. Survey of Pain Attitudes (SOPA) (including SOPA_35, SOPA_57, SOPA_short) limited evidence of strong psychometric properties

26. Vanderbilt Multidimensional Pain Management Inventory (VMDPMI) limited access to background documentation, limited evidence of psychometric properties, overlaps with other better credentialed instruments

\section{Functional assessment of persistent pain}

The excluded instruments during Step 2 comprised FIE, IFS_CP, KSMBJC, PDQ, RFQ (all for poor evidence of psychometric testing). 


\section{Multidimensional assessment of persistent pain}

Six instruments (one instrument suite) were excluded because the primary function was to measure outcome (POQ suite). Eight instruments were excluded during Step 2 for poor evidence of psychometric testing, comprising HBQP,
HIPSPSQ, MRFA, PCOQ, PCP_Screen, PCO_Ext, POP and VDPQ.

General health/Quality of life assessment of persistent pain

No instruments were excluded during Step 2. 